Florida International University FIU Digital Commons

$11-9-2016$

\title{
Synthesis and Characterization of a Hydrolytically Stable Photochromic Copolymer Containing an N-alkylindolylfulgimide
}

Samina yasmeen

Florida International University, syasm001@fiu.edu

DOI: $10.25148 /$ etd.FIDC001260

Follow this and additional works at: https://digitalcommons.fiu.edu/etd

Part of the Organic Chemistry Commons

\section{Recommended Citation}

yasmeen, Samina, "Synthesis and Characterization of a Hydrolytically Stable Photochromic Copolymer Containing an Nalkylindolylfulgimide" (2016). FIU Electronic Theses and Dissertations. 2725.

https://digitalcommons.fiu.edu/etd/2725 


\title{
FLORIDA INTERNATIONAL UNIVERSITY
}

Miami, Florida

\section{SYNTHESIS AND CHARACTERIZATION OF A HYDROLYTICALLY STABLE PHOTOCHROMIC COPOLYMER CONTAINING AN N-ALKYLINDOLYLFULGIMIDE}

\author{
A thesis submitted in partial fulfillment of \\ the requirements for the degree of \\ MASTER OF SCIENCE \\ in \\ CHEMISTRY \\ by
}

Samina Yasmeen 
To: Dean Michael R. Heithaus

College of Arts, Sciences and Education

This thesis, written by Samina Yasmeen, and entitled Synthesis and Characterization of a Hydrolytically Stable Photochromic Copolymer Containing an $\mathrm{N}$-alkylindolylfulgimide, having been approved in respect to style and intellectual content, is referred to you for judgment.

We have read this thesis and recommend that it be approved.

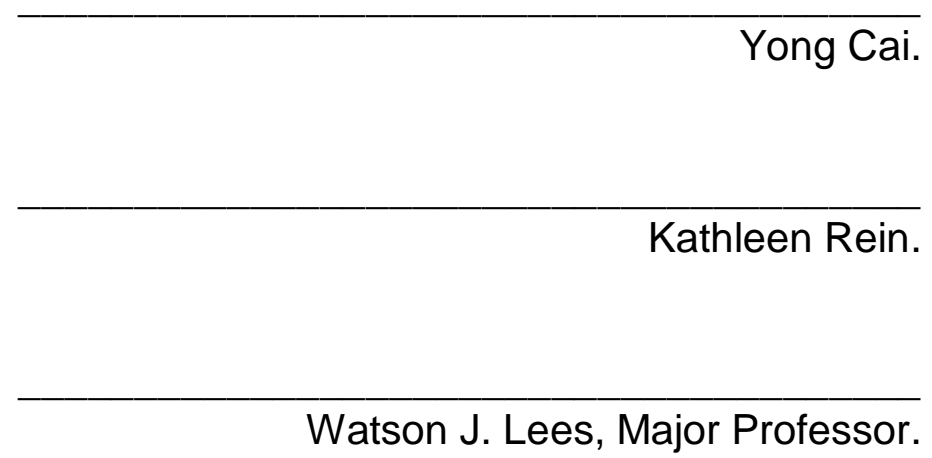

Date of Defense: November 09, 2016

The thesis of Samina Yasmeen is approved.

Dean Michael R. Heithaus

College of Arts, Sciences, and Education

Vice President for Research and Economic Development and Dean of University Graduate School

Florida International University, 2016 


\section{DEDICATION}

I dedicate my thesis work to my wonderful family, husband Muhammad Zubair Ahmad and children Areeb Khokhar, Arfee Khokhar, and Arham Khokhar. A special feeling of gratitude to my loving parents, Muhammad Yaseen and Shamium Akhtar whose words of encouragement and prays are always with me. Very special thanks to my friends, Ms. Dora Mesa and Mrs. Tuzeen Kausar. Without their understanding, encouragement, support and love, the completion of this work would not have been possible. 


\section{ACKNOWLEDGMENTS}

In the past over 3 years of graduate study in FIU, I am so grateful for the valuable assistance from many people. First of all, I would like to thank my professor, Dr. Watson J. Lees, for his incredible supervision, guidance and support. Dr. Lees is the kindest person who I have ever met in my life. He is always nice and patient to his students. I am so lucky to have Dr. Lees being my mentor.

I would like to thank Dr. Yong Cai, and Dr. Kathleen Rein to serve as my committee members. I appreciate their valuable time, insightful advices, and precious suggestions to my research.

I would like to thank Mr. Yali Hsu for his help in operation of NMR, folks working in stockroom for their help in supplies and graduate secretary Mrs. Magali Autie for caring all the time. I also like to thank all members in Dr. Lees' research group: Mr. Ram Marahatta, Ms. Michelle Moats, and Ms. Na Zhang.

Also, I would like to express my sincere thanks to Department of Chemistry \& Biochemistry for the Teaching Assistant. Last but not least, I want to express my appreciation to all those who have helped me in any way during my three years of studies at FIU. 


\section{ABSTRACT OF THE THESIS \\ SYNTHESIS AND CHARACTERIZATION OF HYDROLYTICALLY STABLE \\ PHOTOCHROMIC COPOLYMER \\ CONTAINING AN N-ALKYLINDOLYLFULGIMIDE \\ By}

Samina Yasmeen

Florida International University, 2016

Miami, Florida

Professor Watson J. Lees, Major Professor

Fulgides and fulgimides comprise one class of thermally irreversible photochromic organic compounds. Light dependent isomerization, has made these organic molecules promising materials for several applications, including optical memory devices, and switches. Hydrolytic stability of fulgides and fulgimides is crucial for their practical applications in biological systems and humid environments. Fulgimides, the most important derivative of fulgides, have a succinimide ring, which, unlike the anhydride ring, of fulgides, is resistant to hydrolytic degradation. A novel $\mathrm{N}$-alkylindolylfulgimide was synthesized and copolymerized with acrylamide. The photochromic and hydrolytic properties of the copolymer in phosphate $(\mathrm{pH} 7.4)$ and acetate $(\mathrm{pH} 5.0)$ buffer solutions were characterized. The $N$-alkylindolylfulgimide based copolymer exhibited significantly enhanced hydrolytic stability (50 times better in phosphate buffer) and similar photochromic properties as a copolymer containing an $\mathrm{N}$-arylindolylfulgimide. 


\section{TABLE OF CONTENTS}

CHAPTER

PAGE

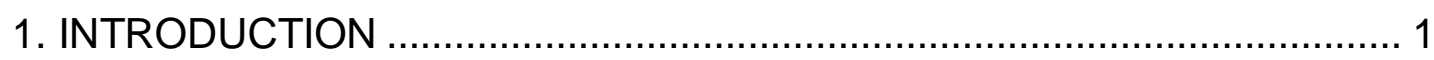

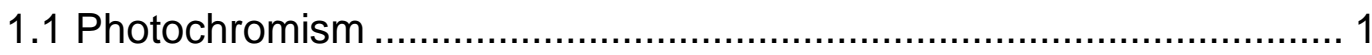

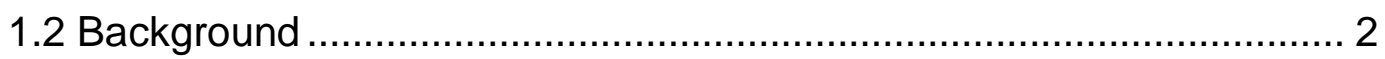

1.3 Chemical processes involved in organic photochromism .................... 5

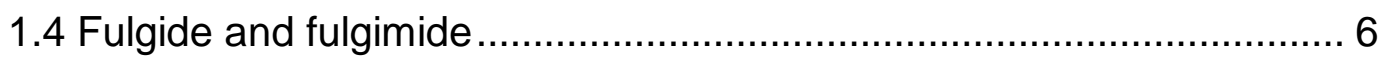

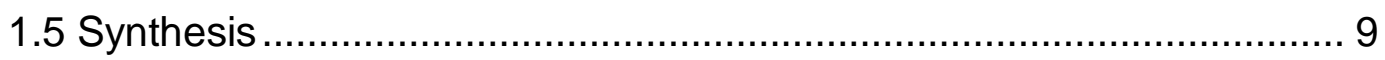

1.6 Photochromic properties of indolylfulgides and indolylfulgimides ...... 16

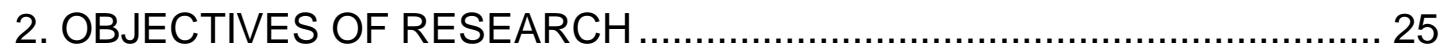

2.1 Synthesis of a polymerizable photochromic fulgimide monomer ....... 26

2.2 Synthesis of a linear fulgimide-co-PAA copolymer............................ 26

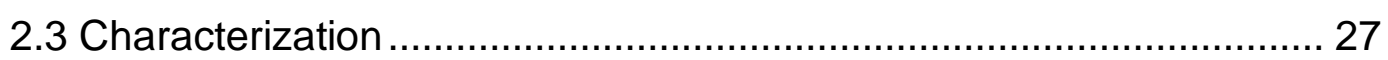

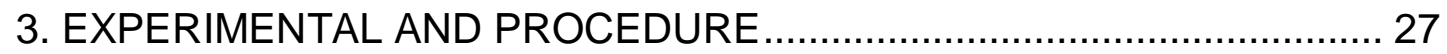

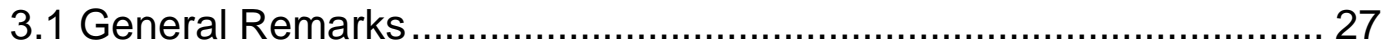

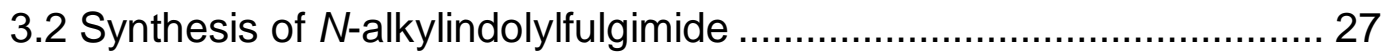

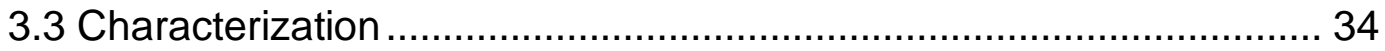

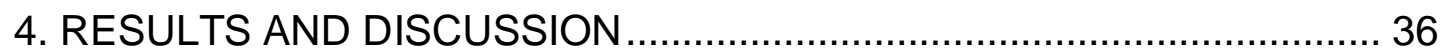

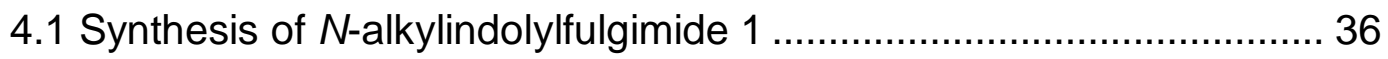

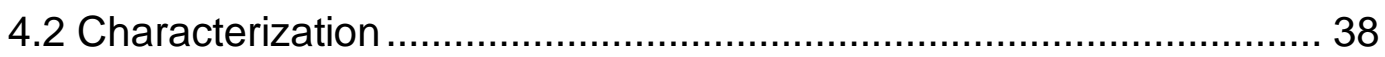

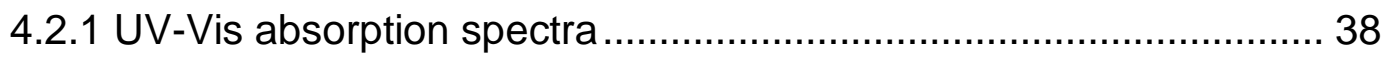

5. CONCLUSION AND FUTURE DIRECTIONS …….............................. 44

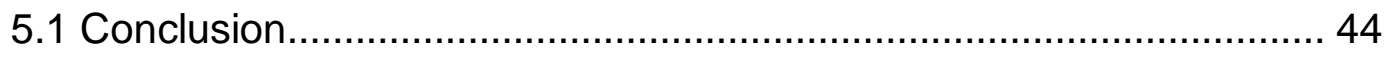

5.2 Future research works .............................................................. 45

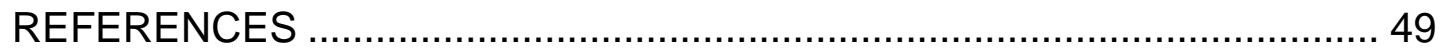




\section{LIST OF FIGURES}

FIGURE

PAGE

1. Photochromic reaction and absorption spectra of photochromic ......................1

2. Important classes of organic photochromic compounds..................................3

3. General structures of fulgides and fulgimides...........................................

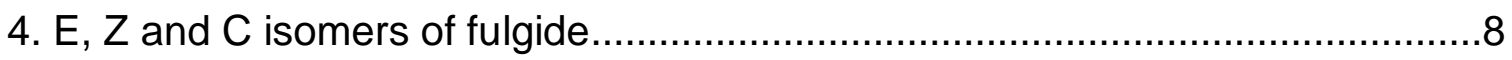

5. Examples of heteorcyclic fulgides synthesized by Matsushima et al. ${ }^{25,26}$..........9

6. Conrotatory ring closure of a fulgide ........................................................10

7. UV-Vis absorption spectra of a photochromic fulgide....................................19

8. Absorption maxima of furanyl, thienyl and pyrrylfulgides in toluene................19

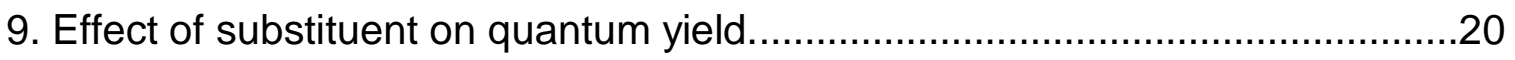

10. Examples of heterocyclic fulgides synthesized by Matsushima et al. ${ }^{25,26}$

11. Proposed mechanism of 1,5 sigmatropic rearrangement and tautomerization

12. Hydrolytically stable fulgimide synthesized by Matsushima et al.

13. Photoswitchable energy transfer compound containing a fulgimide. .24

14. Molecular memory by Rentzepis. .25

15. Molecular device of porphyrin-fulgimide dyad 60 .26

16. UV-Vis absorption spectra of $\mathrm{N}$ - alkylindolylfulgimide 1 in toluene. 38

17. UV-Vis absorption spectra of 1-co-PAA in buffer. 39

18. The $\mathrm{E}$ form decomposition in $50 \mathrm{mM}$ phosphate $(\mathrm{pH} 7.4)$ and $50 \mathrm{mM}$ acetate buffer (pH 5.0). Data for 2-co-PAA from ref.65.

19. The $\mathrm{C}$ form decomposition in $50 \mathrm{mM}$ phosphate $(\mathrm{pH} 7.4)$ and $50 \mathrm{mM}$ acetate buffer ( $\mathrm{pH}$ 5.0). Data for 2-co-PAA from ref. 65. 
20. Decomposition of $\mathrm{N}$-alkylfulgimide 1 and $\mathrm{N}$-arylfulgimide 2 in toluene at $80^{\circ} \mathrm{C}$. Data for $\mathrm{N}$-arylfulgimide 2 from ref. 65 .

21. Photochemical decomposition of 1-co-PAA and 2-co-PAA in $50 \mathrm{mM}$ Phosphate $(\mathrm{pH} 7.4)$ and $50 \mathrm{mM}$ acetate buffer ( $\mathrm{pH}$ 5.0). Data for 2-co-PAA from ref. 65.

22. Photochemical decomposition of $\mathrm{N}$-alkylfulgimide 1 and $\mathrm{N}$-arylfulgimide 2 in toluene. Data for $\mathrm{N}$-arylfulgimide 2 from ref. 65.

23. Enzyme immobilization by using photochromic copolymer 46 


\section{LIST OF SCHEMES}

SCHEME

PAGE

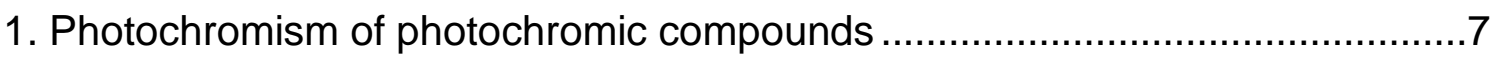

2. Synthesis of fulgide by Stobbe condensation. ..........................................11

3. Mechanism of Stobbe condensation. ………...........................................11

4. Synthetic scheme of indolylfulgide by Yokoyama et al................................12

5. Synthesis of trifluoromethylindolylfulgide by Lees et al. ..............................13

6. Synthetic pathway of fulgimide from fulgide ............................................14

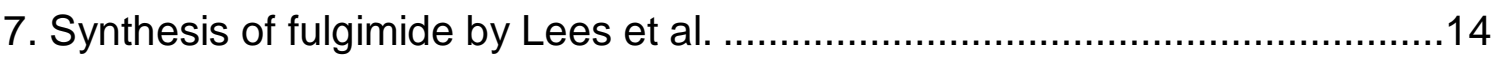

8. Synthetic route of fulgimide by Rentzepis et al. .........................................15

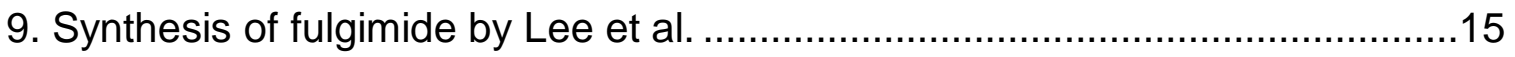

10. Synthesis of fulgimide by Smet et al.......................................................16

11. Linear-copolymer containing indolyfulgide and indolylfulgimidmide ..............17

12. Cross-linked copolymer containg indolylfulgimide ...................................17

13. Proposed synthetic pathway of disubstituted N-Alkylindolylfulgimide $3 \ldots \ldots . . .47$

14. Polymerization of disubstituted N-Alkylindolylfulgimide. ..............................48

15. Proposed synthetic pathway of trifluoromethyl dicycloproyl N-Alkylindolylfulgimide 4. 


\section{INTRODUCTION}

\subsection{Photochromism}

Photochromism can be defined as "The reversible transformation of chemical species, induced in one or both directions by electromagnetic radiation, between two states having observable light absorption in different regions of the spectrum". ${ }^{1}$ For the most part, photochromic systems depend on unimolecular reactions.

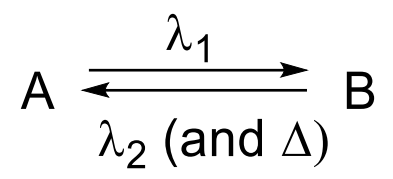

Ordinarily, transformed chemical species "B" has at least one absorption band at a longer wavelength than the absorption bands of species " $A$ ". Generally, the activation wavelength, $\lambda_{1}$ is in the ultraviolet region (190-400 nm), but may also be in the visible region $400-800 \mathrm{~nm}^{1}$

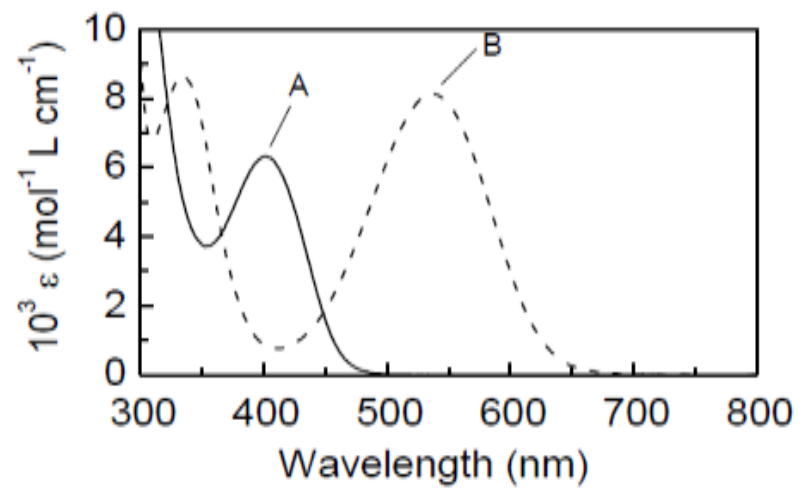

Figure 1. Photochromic reaction and absorption spectra of photochromic Compound.

Spiropyrans, azobenzenes, diarylethenes, fulgides, and fulgimides are traditional examples of organic photochromic molecules. Spiropyrans and azobenzenes are classified into T-type (thermally reversible) photochromes. The 
photoinduced isomeric form is thermally unstable and colors slowly disappeared in the dark at room temperature.

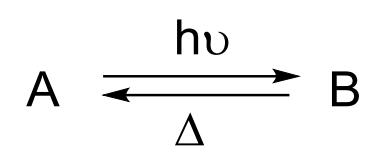

On the other hand, fulgides and diarylethenes are classified into P-type (thermally irreversible, but photochemically reversible) photochromes. In the class of P-type photochromic molecules, the photoinduced isomeric forms are thermally stable in the dark at room temperature. ${ }^{2}$

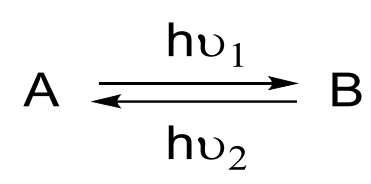

\subsection{Background}

The phenomenon of photochromism was noted for the first time in 1867 when Fritzsche observed the bleaching of a colored tetracene solution in daylight, and its re-coloring at night. ${ }^{3}$ Since then, many photochromic compounds have been described. However, the general interest in photochromic compounds was moderate for about a century. During the 1950s, comprehensive synthetic and mechanistic studies were done, in particular by Hirshberg and Fischer et al. ${ }^{4}$ In the 1960s, research of photochromic compounds expanded rapidly. The main initiative of research was Hirshberg's idea of using the phenomenon of photochromism for photochemical erasable memory. ${ }^{5}$ However, the photodegradation of organic photochromic compounds limited the potential for their applications. Tremendous efforts were made in 70 s-80s to improve the thermal irreversibility of photochromic 
systems. The focus of research was to improve the thermal stability in existing molecules. Unfortunately, all attempts were unsuccessful. ${ }^{2}$ Finally, in the mid1980s the photogenerated colors of diarylethenes and furylfulgides were found to be stable at room temperature. ${ }^{6}$ In 2007 , the most stable fulgide, trifluoromethyl dicyclopropyl indolylfulgide, was reported by Lees et al. to undergo 10,000 coloring and bleaching photochemical cycles before degrading by $13 \%(0.0013 \% /$ cycle. In terms of photochromic performance the indolylfulgide derivative is similar to the best diarylethene derivative $(0.0007 \% /$ cycle $){ }^{7,8}$

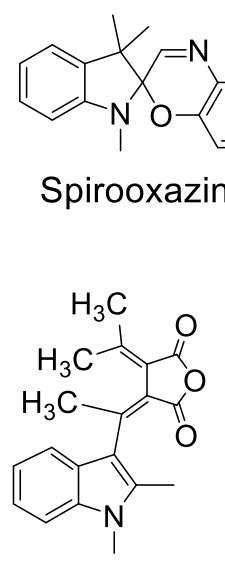

Fulgide

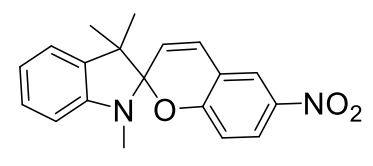

Spiropyran

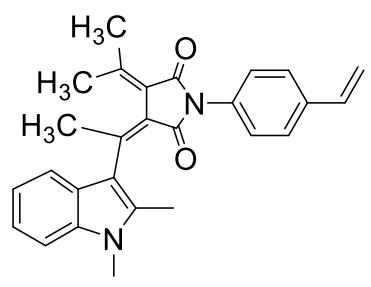

Fulgimide
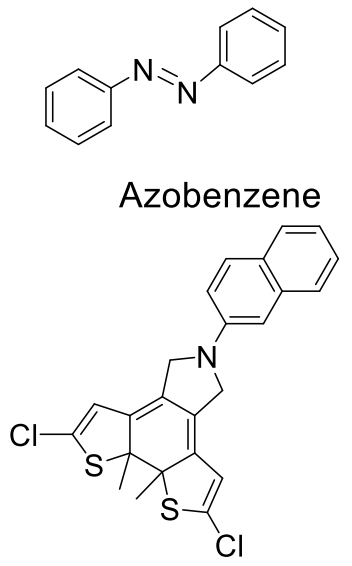

Diarylethene

Figure 2. Important classes of organic photochromic compounds.

Over the past decade, the basic palette of available photochromic compounds has not expanded significantly in photochromic devices. Generally, most of the effort has been devoted to improve the properties of established photochromic compounds. ${ }^{9}$ Spiropyrans, azobenzenes, diarylethenes, fulgides, and fulgimides. ${ }^{2,10}$

Each class of photochromic molecules has a preferred application area. For instance, spiropyrans have a unique feature of increasing the dipole moment during the photoisomerization process from closed to open form. ${ }^{9}$ Spiropyrans 
containing photochromic materials are usually considered a superior photochrome when interaction with charged surfaces and entities is desired. ${ }^{9}$ In 2015 , Song et al. ${ }^{11}$ introduced a spirooxazine contaning high-performance photochromic sensor microchip used for the detection of eleven various multiplex metal ions. However, the low thermal stability of the $C$ form of spiropyrans and spirooxazines has restricted their application in devices. ${ }^{12}$

Usually, azobenzenes containing materials are utilized in actuation and optical memory storage. ${ }^{9}$ The $E / Z$ isomerization of azobenzenes leads to large structural changes, which can be transferred and amplified in suitable host material. ${ }^{9}$ Substituted photochromic azobenzenes are easy to synthesize and are compatible with aqueous environments. ${ }^{13}$ Recently, Liang et al. ${ }^{14}$ reported fully photoinduced molecular tweezers that use on photoswitchable DNA hybridized with azobenzene. For medical applications, one major issue of photochromic azobenzenes is the use of UV light to induce $E / Z$ isomerization. High energy UV photons are detrimental because of their low penetration ability into biological tissues, and the severe cell damage among other unwanted side effects. ${ }^{9}$

On the other hand, diarylethenes undergo large electronic changes upon irradiation with UV light. Photoinduced electronic changes has been utilized in the application of diarylethenes based materials to control the electronic coupling and energy transfer pathways in multicomponent systems. ${ }^{9}$ In 1998, Kawata et al. ${ }^{15}$ introduced the use of diarylethenes in nondestructive readout memory devices. The data were stored in three dimensional photochromic diarylethenes memory. A reflection confocal microscope was used as a readout system. The readout laser 
light had a longer wavelength than the absorption edge of the colored isomer. ${ }^{8}$ Diarylethenes are also known for their high opened-to-closed quantum yield (0.86), and photochemical and thermal stability. However, the closed-to-opened quantum yield is low, the extinction coefficients of both forms are low, and the refractive index changes are not large. ${ }^{3}$

Fulgides and fulgimides are a promising class of organic photochromic compounds. In comparison with fulgides, fulgimides are known for their enhanced thermal stability and copolymerization ability. ${ }^{16,17}$ Fulgimides are preferably used for modulating the structure and function of biomolecules. For example, under photoirridiation a fulgimide attached to a biomolecule can alter the molecular structure and modulate the activity. Fulgides and fulgimides have potential applications in molecular switches, optical storage, optical data processing, waveguides, security and printing, eyewear and leisure products. ${ }^{21}$

\subsection{Chemical processes involved in organic photochromism}

Photochromism is a special case of a photochemical reaction, almost any type of photochemical reaction may be used to produce photochromism with appropriate molecular design. For example, pericyclic reactions take place in spiropyrans, spirooxazines, diarylethenes, fulgides, and fulgimides. ${ }^{18}$ In spirooxazine, upon irriadiation with UV light, the ring opens because a bond breaks between the spiro-carbon and the oxygen. As a result the spiro-carbon becomes $\mathrm{sp}^{2}$ hybridized and planar, then develops a conjugate system by aligning its $p$ -

orbital with the rest of the molecule. The newly formed conjugated system has the ability to absorb photons of visible light, and therefore appears colored. After 
irradiation with visible light, the bond between the carbon and oxygen atoms reforms. Then, the spiro-carbon becomes $\mathrm{sp}^{3}$ hybridized again, and the molecule returns to its colorless state.

Photochromic reactions of diarylethenes and fulgides operate by a $6 \pi-$ electrocyclization. Cis/trans isomerization of azobenzene is an example of a photochromic reaction. ${ }^{19}$ Photochemical reactions of some of the typical families of photochromic compounds are shown in Scheme 1.2,20,21

\subsection{Fulgide and fulgimide}

The general structure of fulgides and fulgimides are presented in Figure 3.

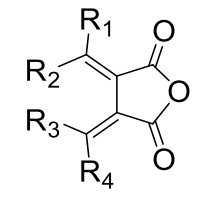

Fulgide

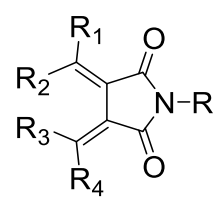

Fulgimide

Figure 3. General structures of fulgides and fulgimides.

Fulgides, the acidic anhydride of 1,3-butadiene-2,3-dicarboxylic acid, and its derivatives were first discovered by Stobbe in $1905 .{ }^{22,23}$ The name "fulgide" was originally given to the bismethylene succinic anhydride, which comes from the Latin fulgere meaning to glitter or shine. In fact, some derivatives of fulgide exhibit a variety of characteristic colors upon exposure to light. ${ }^{24}$ The photochromic fulgides and fulgimides should have an aromatic ring or a double bond as one of 
Scheme 1. Photochromism of photochromic compounds

Spirooxazines:<smiles>[X]c1cc2c(c3ccccc13)N=CC1(O2)N([R])c2ccccc2C1(C)C</smiles>

Close form

Colorless

\section{Diarylethenes:}<smiles>Cc1cc(C2=C(c3cc(C)sc3C)C(F)(F)C(F)(F)C2(F)F)cs1</smiles>

Open form

Colorless
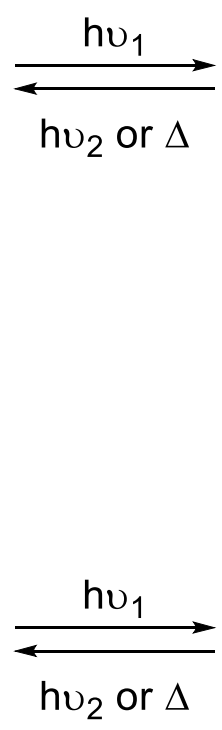

Indolyl fulgides and indolyl fulgimides:<smiles>[X]C(=O)/C(=C(/C)c1c(C)n(C)c2ccccc12)C(C)C</smiles>

Open form Colorless
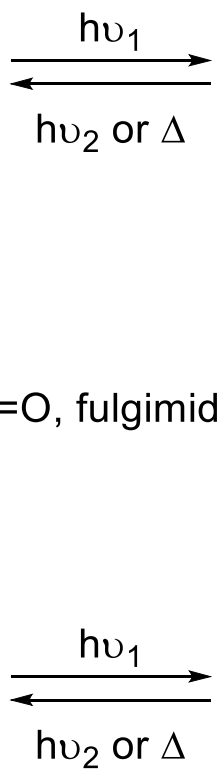

\section{Azocompounds:}

Trans form

Colorless<smiles>c1ccc(/N=N/c2ccccc2)cc1</smiles><smiles>[X]c1cc(O)c(/N=C\C2=[N+]([R])c3ccccc3C2(C)C)c2ccccc12</smiles>

Open form Colored<smiles>CC1=CC(=C2C3=C4C=C(C)C(F)(F)C4(F)SC3(C)C(F)(F)C2(F)F)C(C)(C)[SiH2]1</smiles>

Closed form Colored<smiles>[X]C(=O)C1=C(C(=O)C2=C(C)c3ccccc3N(C)C2(C)C)C(C)(C)C1</smiles>

Closed form Colored

fulgides $X=O$, fulgimides $X=N-R$ 
the substituents, $R_{1}, R_{2}, R_{3}$ or $R_{4}$ at the exomethylene carbon. The aromatic ring or the double bond results in a 1,3,5-hexatriene structure that can undergo $6 \pi$ electrocyclization. The $E / Z$ isomeric forms depend on the arrangement of the substituents ( $R_{1}, R_{2}$ and anhydride ring). One of the isomers, either $E$ or $Z$, may undergo a $6 \pi$-electrocyclization with UV light to produce a colored cyclic isomer, C form, Figure 4.

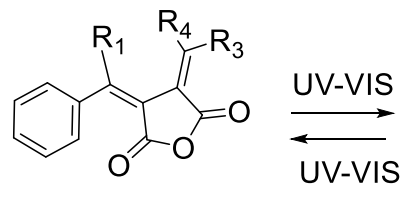

E form

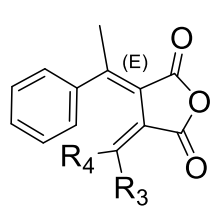

$Z$ form

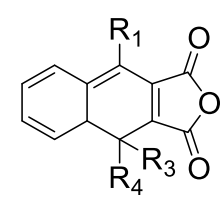

$C$ form

Figure 4. $E, Z$ and $C$ isomers of fulgide

In 1988, Matsushima synthesized several heteroaromatic fulgides, and studied their thermal and photochemical stability in poly(methyl methacrylate) (PMMA) films, Figure $5 . .^{25,26}$ Among these different fulgide derivatives, 3-indolylfulgide was recognized to have high thermal and photochemical stability, large quantum yields, large molar absorption coefficients, and an absorption maxima in the visible region. The succinimide derivatives of fulgides are fulgimides, which were first introduced by Heller. ${ }^{27,28}$ Fulgimides are one of the most important derivatives of fulgides. The 3-indolylfulgimides were recognized to have the same advantageous properties as the corresponding fulgides. ${ }^{29}$ Unlike fulgides, fulgimides are hydrolytically stable in protic solvents and the succinimide ring of fulgimides allows another substituent to be attached via the nitrogen atom while keeping the promising photochromic properties. These properties lead to the application of fulgimides in erasable optical recording materials and photoswitchable optical devices. In general, fulgimides 
can be synthesized by a variety of methods, but most often they are prepared from their precursor fulgides. ${ }^{30,} 31$

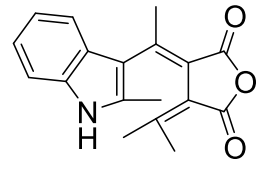

Indolylfulgide

1

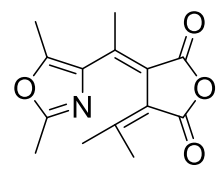

Oxazolylfulgide

2

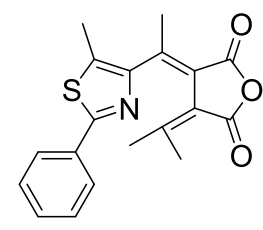

Thiazolylfulgide

3

Figure 5. Examples of heteorcyclic fulgides synthesized by Matsushima et al..$^{25,26}$

\subsubsection{Photochemical reaction of fulgides and fulgimides}

The photochemical reaction of fulgides and fulgimides involves a pericyclic reaction. According to Heller, the $C$-form is formed by an excitation of electrons from $n$ to $\pi^{*}$. The orbitals are rearranged by a conrotatory movement in accordance with the Woodward-Hoffmann selection rules. ${ }^{9}$ However, Becker proposed a different mechanism after using microsecond and nanosecond laser flash photolysis. Becker suggested that the photocyclization reaction of a fulgide is a result of $\pi$ to $\pi^{*}$ rather than $n$ to $\pi^{*}$ excitation, ${ }^{10}$ Figure 6 . The $\pi$ to $\pi^{*}$ excitation was confirmed by the picosecond laser photolysis studies of Partheopouls and Rentzepis, ${ }^{34}$ and Kurita and Takeda. ${ }^{36}$

\subsection{Synthesis}

\subsubsection{Synthesis of fulgides}

Generally fulgides are synthesized by a Stobbe condensation, which involves the condensation of an aryl aldehyde or ketone with a succinate derivative to form a half ester, followed by acid hydrolysis of the half ester and dehydration of the 


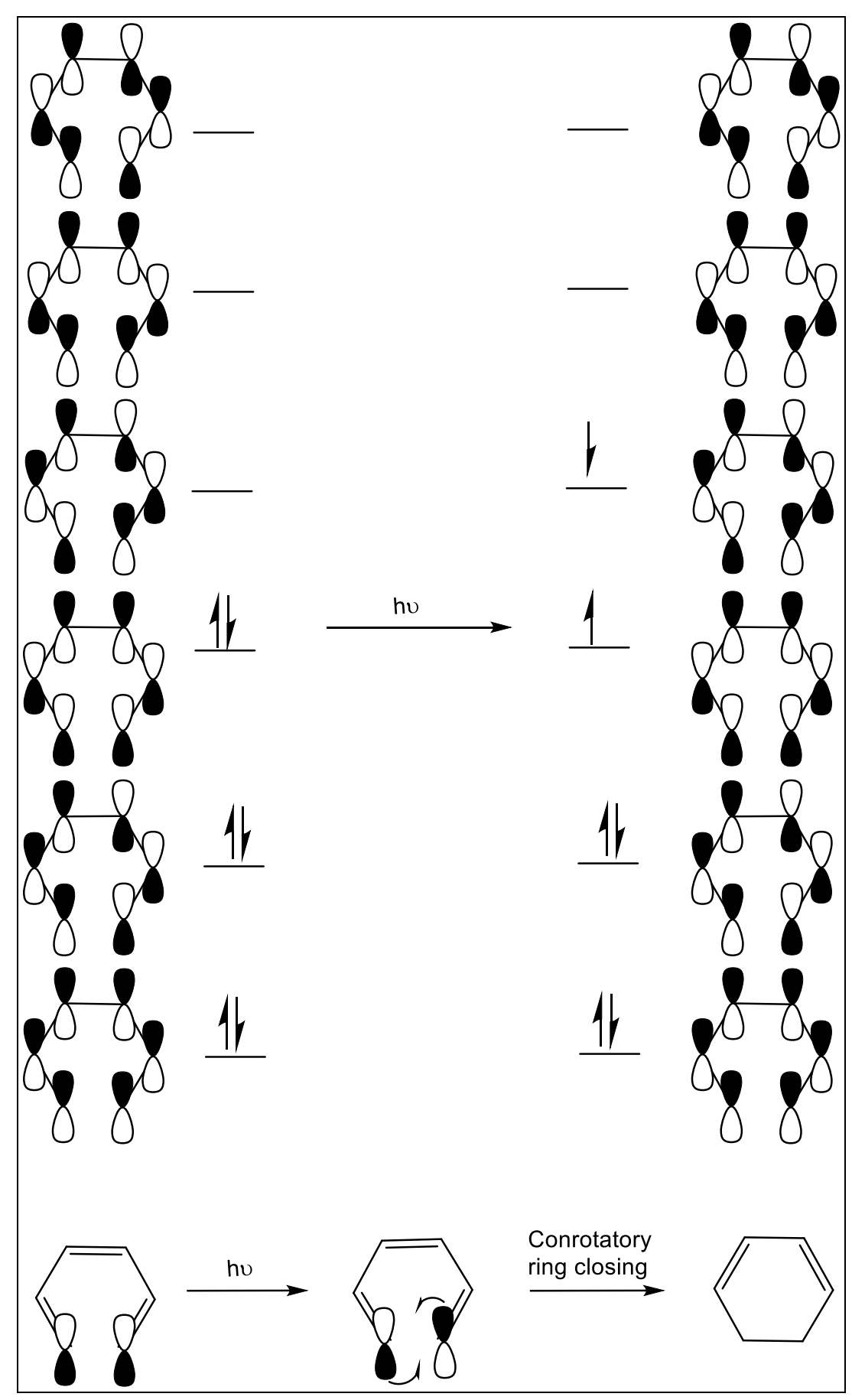

Figure 6. Conrotatory ring closure of a fulgide.

resulting diacid, Scheme $2 .{ }^{27}$ The first step of a Stobbe condensation is the formation of an ester enolate by deprotonation of the $\alpha$-carbon of the diethyl 
succinate. The next step is the formation of a $\beta$-alkoxy ester intermediate, followed by lactone formation via intramolecular acyl substitution reaction. Then, the lactone ring is opened to an acid via an elimination reaction under basic conditions. The remaining ester is then hydrolyzed and the resulting diacid dehydrated to obtain the photochromic fulgide, Scheme $3 .{ }^{27} \mathrm{~A}$ significant hurdle in the implementation of a Stobbe condensation in the chemical industry is its low yield. ${ }^{32,33}$ Therefore, a modified synthetic route or new synthetic strategy needs to be developed. ${ }^{34}$

Scheme 2. Synthesis of fulgide by Stobbe condensation.

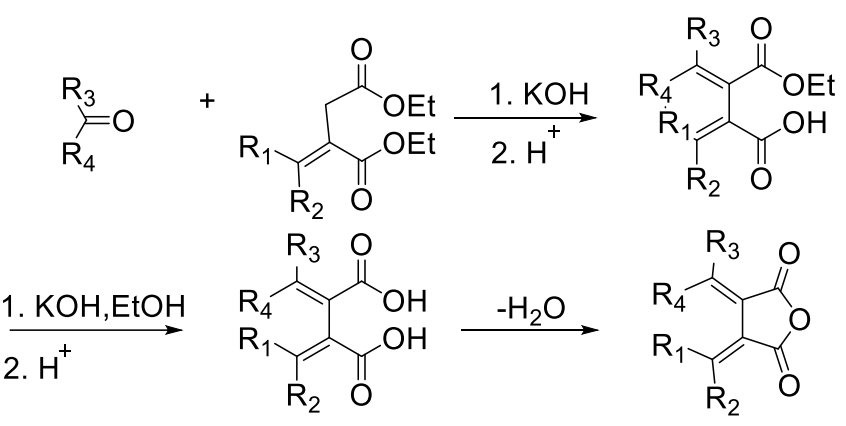

Scheme 3. Mechanism of Stobbe condensation.<smiles>[R]C([R])=C(C(=O)OC)C(=O)OCCC[B]</smiles><smiles>[R]C(=O)[C@H](CC)C(C(=O)OCC)C(=O)OCC</smiles>

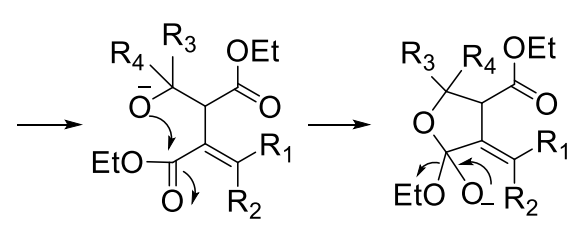

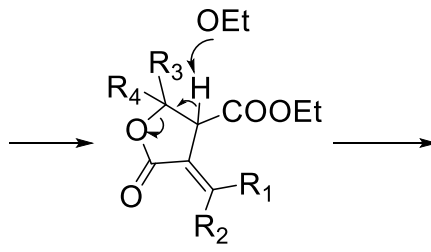<smiles>[R]C([R])=C(C(=O)O)C(=O)OCC[CH-]C</smiles><smiles>[R]C([R])=C(C(=O)O)C(=O)OCC</smiles>

In 1996, Yokoyama et al. reported a trifluoromethylindolylfulgide with remarkable thermal stability. ${ }^{32}$ The first synthetic step was the reaction of $1,2-$ dimethylindole with trifluoracetyltrifluoromethanesulfonate. The trifluoroacetylindole was obtained in $42 \%$ yield. Then 1,2-dimethyl-3- 
trifluoroacetylindole was condensed with dimethylisopropylidene succinate via a Stobbe condensation. The fulgide was obtained in $3 \%$ yield by hydrolysis under basic condition followed by dehydration with imidazole-trifluoroacetate, Scheme 4 . The overall yield of the final product, indolylfulgide, was only $1 \%$. The low yield of the final product is a hurdle to the further application of the synthetic route. ${ }^{32}$

\section{Scheme 4. Synthetic scheme of indolylfulgide by Yokoyama et al.}

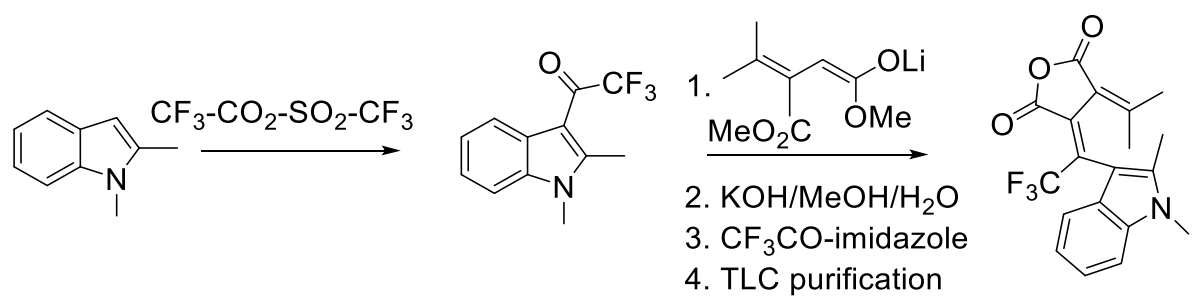

In 2001, Lees et al. ${ }^{17}$ introduced a versatile synthetic route for the synthesis of fulgides. The synthetic strategy was improved by modification of the Stobbe condensation. In the first step, diethyl isopropylidenesuccinate was obtained in $75 \%$ yield. The synthesis involved the reaction of diethyl succinate with acetone. In the second step, 1,2-dimethyl-3-trifluoroacetylindole was obtained with $96 \%$ yield by reacting 1,2-dimetylindole with trifluoroacetic anhydride. Next, 1,2dimethyl-3-trifluoroacetylindole was reacted with diethyl isopropylidenesuccinate in the presence of a strong base, lithium diisopropylamide (LDA), at $-78^{\circ} \mathrm{C}$ in toluene. A mixture of cis/trans lactones was obtained in $38 \%$ yield. The mixture of cis/trans lactones was hydrolyzed with $\mathrm{NaH}$ followed by the addition of water to form the dicarboxylic acid intermediate. Then acetic anhydride was used to dehydrate the dicarboxylic acid intermediate resulting in trifluoromethylindolylfulgide with $83 \%$ yield from the lactones. The new methodology allowed the preparation of a variety of indolylfulgides with reasonable 
yield. The application of the new methodology was expected to improve the yield of fluorinated as well as non-fluorinated indolylfulgide derivatives.

Scheme 5. Synthesis of trifluoromethylindolylfulgide by Lees et al.
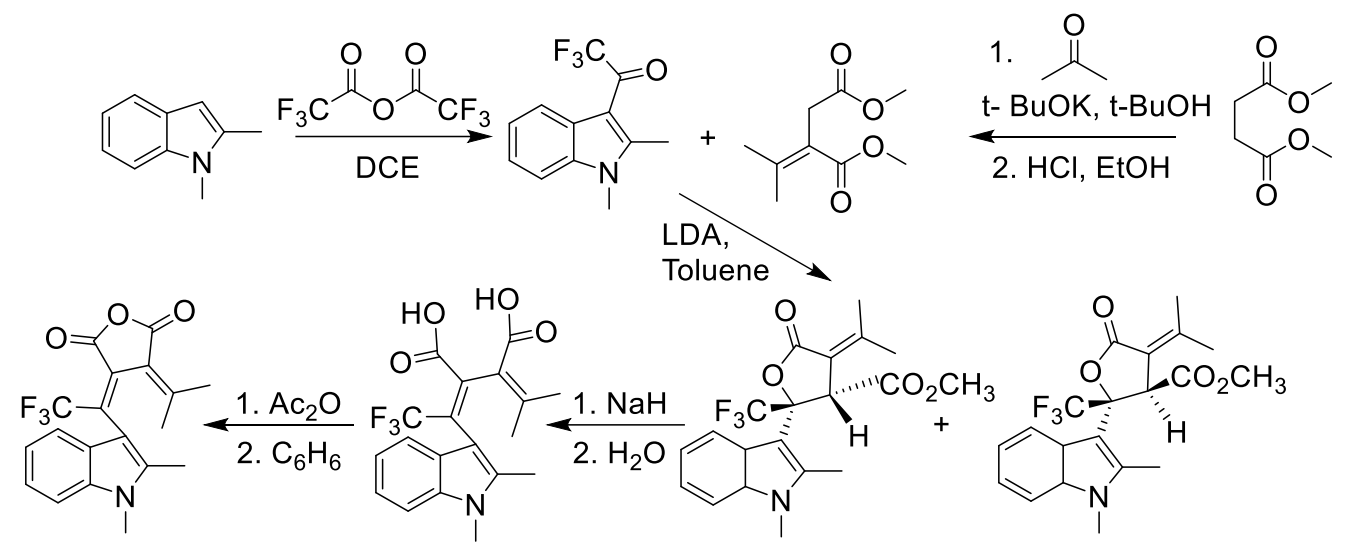

\subsubsection{Synthesis of fulgimides}

There are three different synthetic pathways to fulgimides. In synthetic route I, the key intermediate, succinamic acid, was obtained by reaction of the parent fulgide with a primary amine. Subsequent dehydration of the succinamic acid yields the photochromic fulgimide. In synthetic pathway II, the key intermediate, succinamic acid, was obtained by reacting the succinic half-ester with a Grignard salt of the amine followed by subsequent dehydration to produce photochromic fulgimide. In synthetic pathway III, the first step was the synthesis of non- $N$ substituted fulgimide from parent fulgide, followed by the addition of a substituent at the nitrogen of the imide ring, Scheme, $6 .{ }^{35}$

It was previously reported that synthetic pathway I was the highest yielding and the most common for the synthesis of fulgimides. Lees et al. ${ }^{36}$ adopted synthetic pathway I to synthesize a series of fluorinated indolylfulgimides from the 


\section{Scheme 6. Synthetic pathway of fulgimide from fulgide}

Path I<smiles>[R]C([R])=C1C(=O)OC(=O)C1=C([R])[R]</smiles><smiles>[R]NC(=O)c1c([R])c([R])c(C(=O)O)c([R2])c1[R]</smiles><smiles>[R]C([R])=C1C(=O)N([R])C(=O)C1=C([R])[R]</smiles>

Path II<smiles>[R]C([R])=C(C(=O)O)C(C(=O)O)=C([R])[R]</smiles><smiles>[R]NC(=O)c1c([R])c([R])c(C(=O)O)c([R2])c1[R18]</smiles><smiles>[R]C([R])=C1C(=O)N([R])C(=O)C1=C([R])[R]</smiles>

Path III<smiles></smiles>

parent fulgide, Scheme $7 .{ }^{17}$ The parent fulgide was treated with an aniline derivative in the presence of LDA or $\mathrm{NaH}$ to obtain the succinamic acid intermediate. Then, the fulgimide was obtained by dehydration of the succinamic acid intermediate with acetic anhydride. The reported yield was up to $64 \%$.

\section{Scheme 7. Synthesis of fulgimide by Lees et al.}

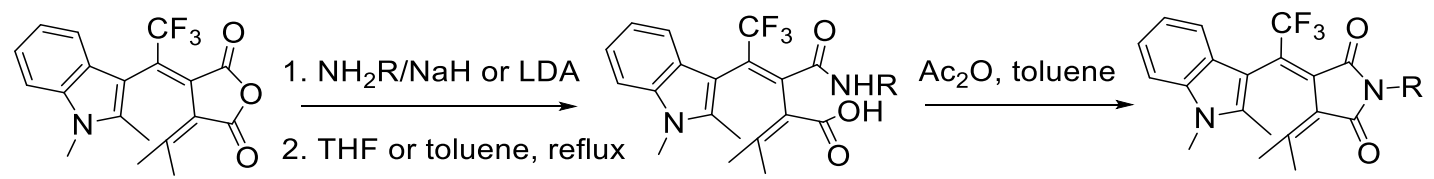

A new procedure for the synthesis of imides under mild reaction conditions was first developed by Toru ${ }^{37}$ and then Rentzepis applied it to the synthesis of a series of fulgimide derivatives in $80 \%{ }^{38}$ yield, Scheme 8 . The synthesis involves the treatment of an anhydride with an amine, producing the amic acid intermediate. A Lewis acid and hexamethyldisilazane (HMDS) were used as dehydrating agents to produce the fulgimide. The proposed mechanism of cyclization is that the Lewis 
acid and HMDS promotes silylation of the amic acid to a labile trimethylsilyl ester derivative followed by thermal deoxysilylation to give the imide.

\section{Scheme 8. Synthetic route of fulgimide by Rentzepis et al.}
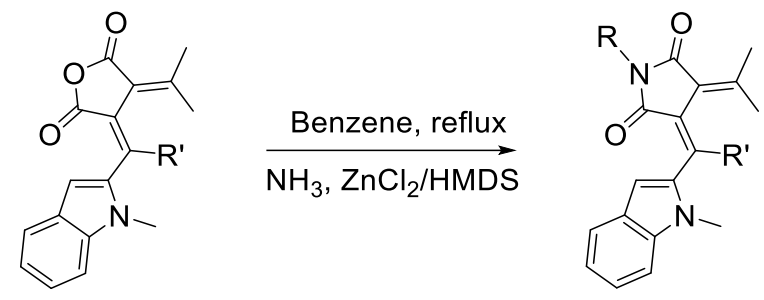

In search of developing an environment friendly method with the use of less solvents for the synthesis of fulgimides, Lee et al. ${ }^{39}$ explored a fast, efficient and low cost synthetic method using microwave technology. A thienylfulgimide was synthesized in a conventional microwave oven. In the first step of the synthesis, the mixture of a thienylfulgide and a bromo-amine was reacted under microwave irradiation. Then, the succinamic acid intermediate was formed that subsequently underwent the dehydration process by acetic anhydride providing a fulgimide in a $85 \%$ yield, Scheme 9

\section{Scheme 9. Synthesis of fulgimide by Lee et al.}

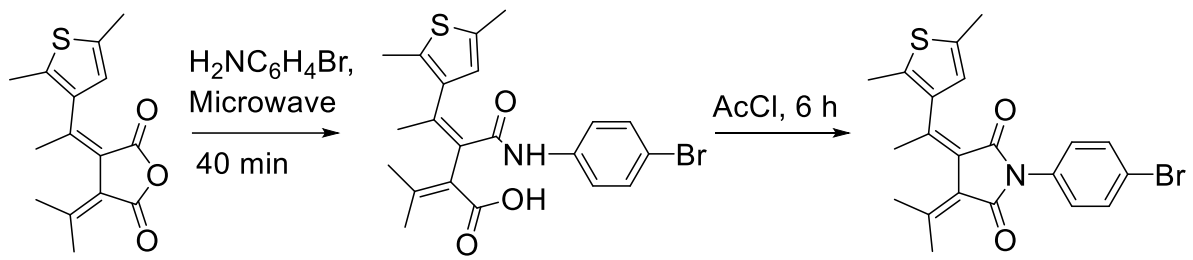

Smet et al. ${ }^{40}$ adopted a third synthetic pathway for the synthesis of furylfulgimide. The parent furylfulgide was reacted with ammonia in acetone, and provided a non $N$-substituted furylfulgimide with $58 \%$ yield. The non $N$-substituted furylfulgimide was reacted with 4-vinylbenzylbromide in the presence of $\mathrm{Cu}$ - 
powder. The product $N$-p-methylstyryl furylfulgimide was obtained in $68 \%$ yield, Scheme 10.

\section{Scheme 10. Synthesis of fulgimide by Smet et al.}<smiles>CC(C)=C1C(=O)OC(=O)C1=C(C)c1cc(C)oc1C</smiles><smiles>CC(C)=C1C(=O)NC(=O)C1=C(C)c1c(C)oc(C)c1C</smiles><smiles>C=Cc1ccc(CN2C(=O)C(=C(C)C)C(=C(C)c3cc(C)oc3C)C2=O)cc1</smiles>

\subsubsection{Synthesis of copolymer containing fulgide or fulgimide}

Most of the optoelectronic devices, for example 3D optical memory devices, demand photochromic material at higher concentrations and in the robust medium

such as beads, films and moldable materials.. ${ }^{41}$ Rentzepis et al. ${ }^{42,43}$ synthesized a series of indolylfulgide and indolylfulgimide containing copolymers. The linear and crossed linked copolymers were made by treating fulgides or fulgimides with methyl methacrylate (MMA). Polymerization was carried out via a free radical mechanism with azobisisobutyronitrile (AIBN). The linear copolymers were soluble in organic solvents but the cross linked copolymers were insoluble in any solvent. Both types of polymers exhibit similar photochromic properties as their corresponding monomers, Schemes 11 and 12.

\subsection{Photochromic properties of indolylfulgides and indolylfulgimides}

The photochromic properties of fulgides and fulgimides such as UV-Vis absorption spectra, photochromic quantum yield, and photochemical and thermal stability are very similar when they are compared in solution and in solid polymer films. The measurement of these properties determines the best photochromic 
Scheme 11. Linear-copolymer containing indolyfulgide and indolylfulgimidmide
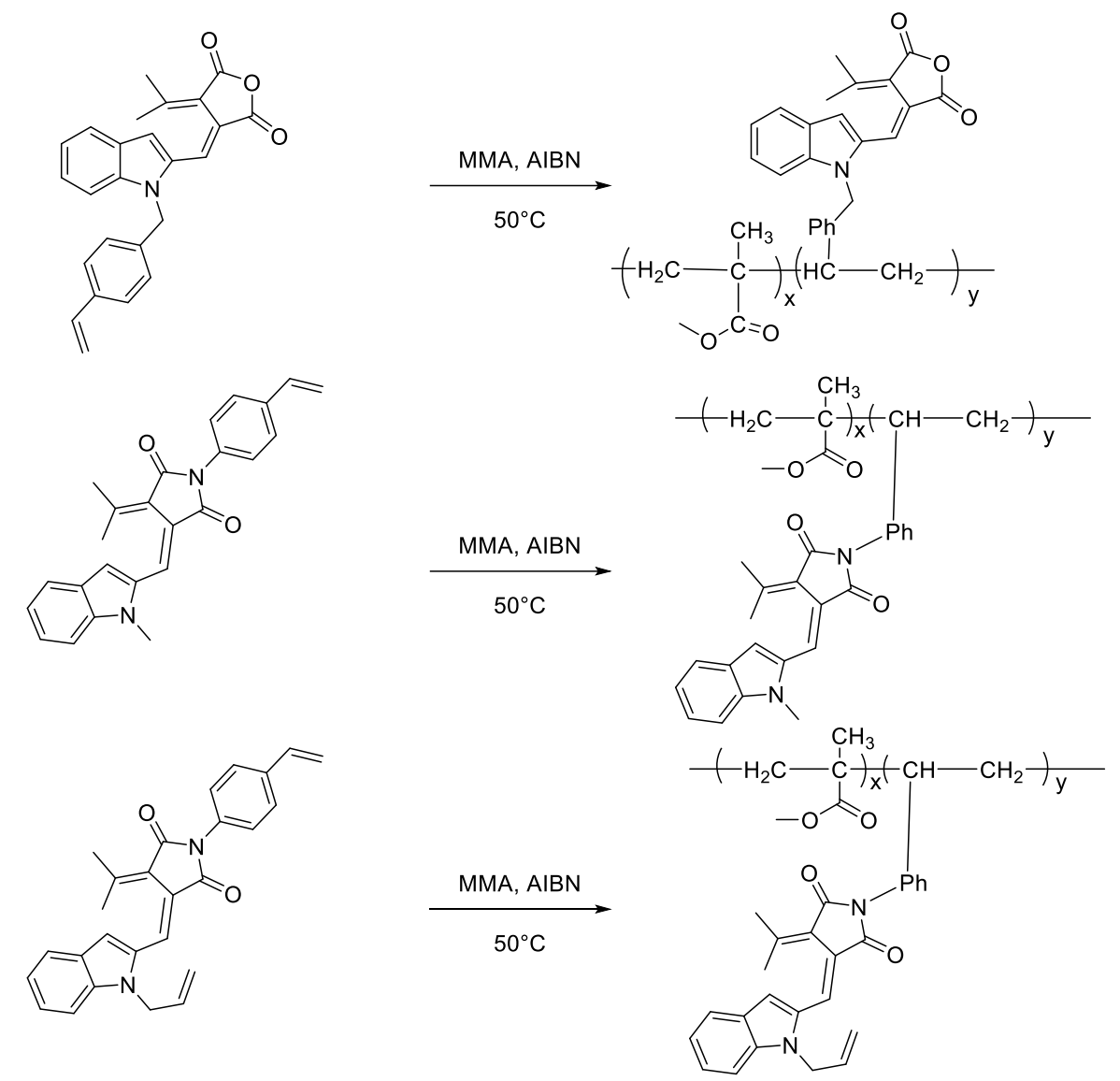

Scheme 12. Cross-linked copolymer containg indolylfulgimide

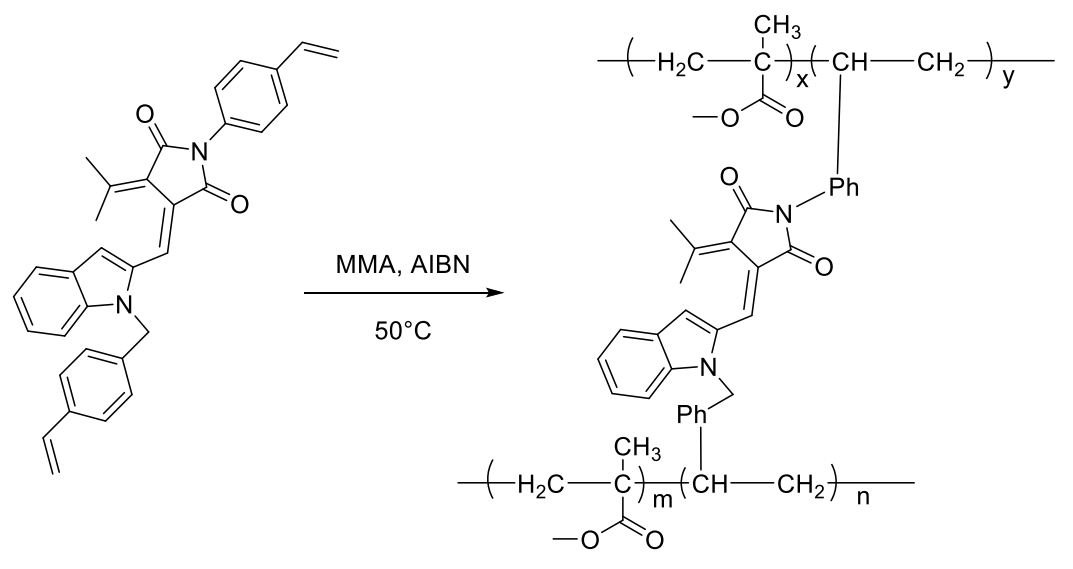


system for each application. ${ }^{27,44}$ Many experimental studies on the synthesis of new fulgides and investigations of their photochromic properties have been conducted, but only a few studies have focused on their thermal stabilities. ${ }^{45}$ Fulgimides are known for their excellent photochromic properties as well as being highly resistant to solvolytic degradation in comparison to fulgides.

\subsubsection{UV-Visible absorption spectra}

The identification of photochromic molecules is best documented by UVVisible spectroscopy (UV-Vis). The $E / Z$ forms and the $C$ form of fulgides/fulgimides exhibit different absorption spectra. Generally, the absorption maxima of the $E$ form and $Z$ form are similar to each other while the absorption maximum of the $C$ form is bathochromic to the absorption maxima of the $E / Z$ isomers. When a mixture of $E / Z$ forms of a fulgimide is irradiated with visible light, a conrotatory ring-closing reaction occurs in agreement with the Woodward and Hoffmann rules and the $C$ form appears in the visible region of the spectrum. ${ }^{27}$ In heteroatomic fulgides, the $C$ form has a bathochromic shift because of the electron-donating ability of the heterocyclic groups. The red shift suggests the extended conjugation of heteroatoms with a carbonyl group of the fulgimide. ${ }^{46}$

Indolylfulgides have three thermally stable isomers, $E, Z$, and $C$ form; each with a distinct UV-Vis absorption spectrum. The three isomers can transform according to the photochromic reactions associated with $\mathrm{P}$ type photochromism. ${ }^{47}$ Through these reactions, the $E / Z$ forms transform to the $C$ form under UV light with limited efficiency. Irradiation with visible light transforms the $C$ form to either $E$ or Z form via an electrocyclic ring-opening reaction. In 1984, llge et al. ${ }^{48}$ investigated 


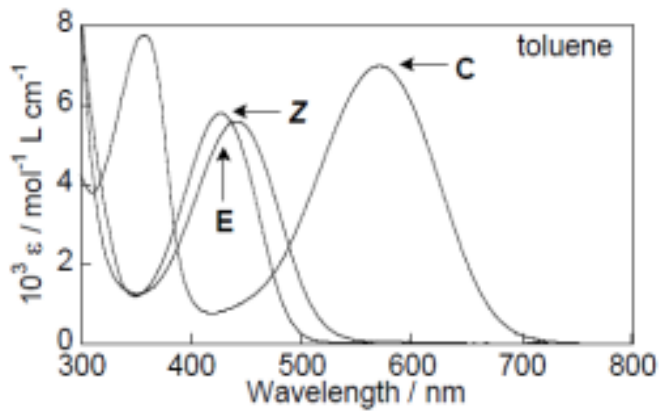

Figure 7. UV-Vis absorption spectra of a photochromic fulgide.
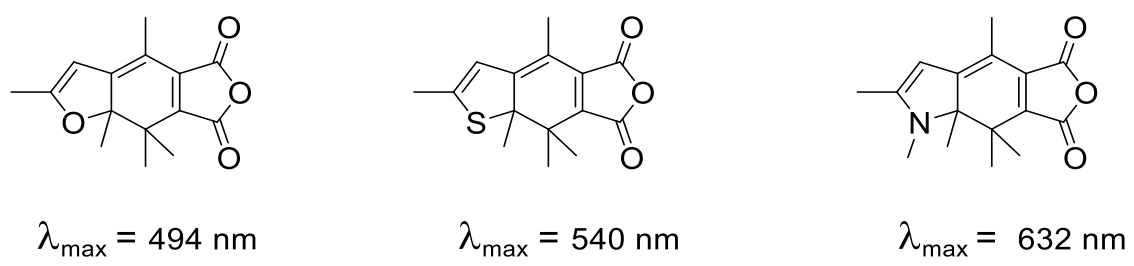

Figure 8. Absorption maxima of furanyl, thienyl and pyrrylfulgides in toluene. the effect of heterocyclic substituent, on the absorption maxima of the cyclic form of fulgides. Absorption maxima tended to red shift with the electron-donating ability of the heterocyclic group, Figure 8.

\subsubsection{Quantum yield}

The quantum yield is a measure of the efficiency of the photochromic reaction and can be defined as "The number of molecules that undergo the photochromic reaction per photon absorbed". ${ }^{49}$ Fast and effective photochromic reactions are possible with low energy light sources if the quantum yields are high. Once a new photochromic molecule is synthesized, light-induced conversion efficiencies as well as the reaction times are normally determined by measuring absolute quantum yield. ${ }^{49}$ Quantum yields of the $E, Z$ and $C$ forms of fulgides/fulgimides can be measured in various solvents and in different polymers. ${ }^{50}$ Rentezpis et al. ${ }^{12}$ measured the solvent polarity dependance of quantum yields for 2-indolylfulgides. 
Quantum yields of both ring closing (coloration) and ring opening (decoloration) depend upon the polarity of the solvent. In a polar solvent, such as acetonitrile, the quantum yield was 0.1 . In a nonpolar solvent, such as hexanes, the quantum yield was found to increase by a factor of 2 . The reason for the low quantum yield in polar solvents is because in the excited state the molecule has a large dipole moment, which is stabilized by the polar solvent and thus the reaction becomes uphill in terms of the activation energy. ${ }^{12}$

Yokoyama and Kurita demonstrated the effect of electron-donating substituents on the quantum yield. The quantum yield of photocyclization reaction decreased in the order $\mathrm{H}-, \mathrm{MeS}-, \mathrm{MeO}-$, and $\mathrm{Me}_{2} \mathrm{~N}-$. The compound having a $\mathrm{Me}_{2} \mathrm{~N}$ - substituent at the 5th position is highly resistant towards ring opening (bleaching reaction). ${ }^{27,35}$
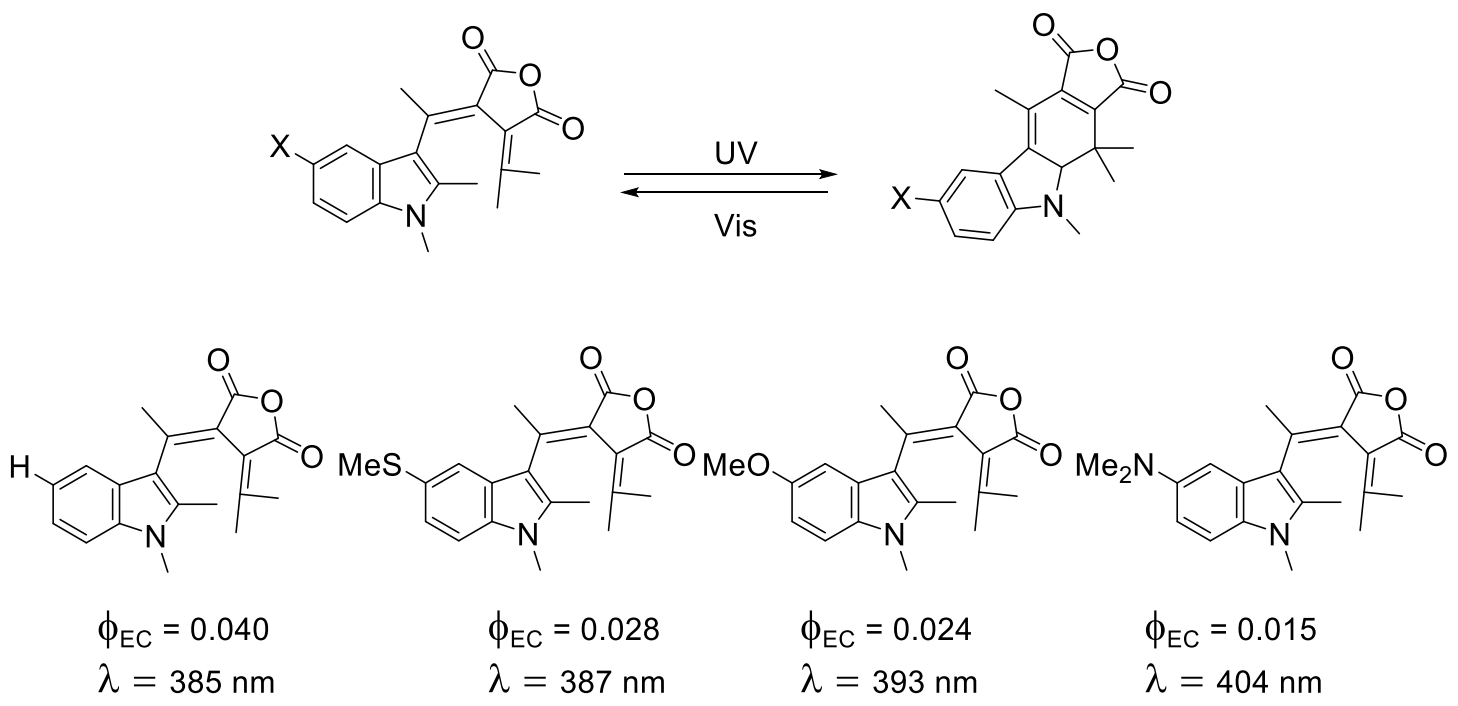

Figure 9. Effect of substituent on quantum yield.

\subsubsection{Thermal stability}

Some optoelectronic devices are expected to maintain viability at $50^{\circ} \mathrm{C}$ for prolonged periods. Therefore, it is very important that the isomers of photochromic 
compounds should be thermally stable at elevated temperature. Practically, photochromic compounds have found limited application in optical information storage devices because of the lack of thermal stability of the colored form. ${ }^{51}$ Among all the subclasses of fulgides, indolylfulgides have attracted special attention because of their enhanced photochemical and thermal stability. The isomeric forms of photochromic indolylfulgides ( $E, Z$ and $C$ forms) when dissolved in deuterated chloroform, hexanes or acetonitrile and kept in the dark, did not show thermal decomposition at room temperature even after one month. The $C$ form of trifluoromethyl substituted indolylfulgides were found to be very stable, because no change in absorption spectra was observed at $80^{\circ} \mathrm{C}$ even after one month. However, the $Z$ form underwent thermal decomposition at $80^{\circ} \mathrm{C} .520,53$ Lees et al. proposed that a 1,5 hydrogen shift is the rate determining step of thermal degradation. It was postulated that thermal stability could be improved by replacing the isopropylidene group with a cycloalkylidene group, and a series of cycloalkylidene indolylfulgides were synthesized with improved thermal stability. ${ }^{54}$

\subsubsection{Photochemical stability}

The photochemical stability is defined as "The percentage of the molecules still retaining photochromic properties after a certain number of ring-closing/ringopening cycles". ${ }^{29}$ The ultimate result of photochemical degradation is the loss of performance over time. Photochemical stability is an important property of photochromic compound for applications in memories and switches. It is difficult to obtain a photochromic compound having high photochemical stability. Matsushima et al. ${ }^{25,26}$ studied the photochemical stability of some heterocyclic fulgides. The 
indolyl and pyrazolyl derivatives showed improved photochemical stability as compared with the furanyl, thienyl and pyrrolyl derivatives, Figure 10.

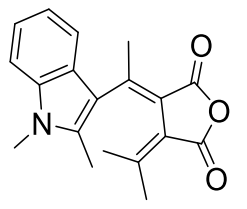

Indolyl

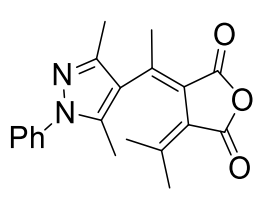

Pyrazolyl

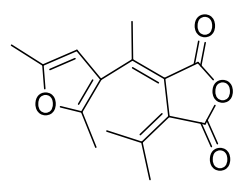

Furryl

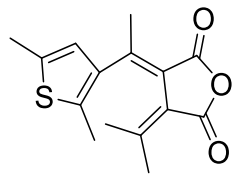

Thienyl

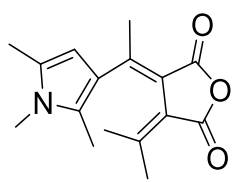

Pyrrolyl

Figure 10. Examples of heterocyclic fulgides synthesized by Matsushima et al. ${ }^{25,26}$

Mechanistic studies of the photochemical decomposition of indolylfulgides were undertaken by Yokoyama ${ }^{32}$ According to the proposed mechanism, the decomposition pathway is a 1,5 hydrogen migration from one of the methyl groups to the carbonyl oxygen on the anhydride ring. A nonphotochromic compound is obtained by the subsequent tautomerization of the resulting compound, Figure 11. Fluorinated indolylfulgides display better photochemical stability as compared to their non-fluorinated analogues. ${ }^{36,53}$ The most promising fulgide for applications in memories and switches is a photochromic trifluoromethyl substituted indolylfulgide reported by Yokoyama and Takahashi. ${ }^{32}$

\subsubsection{Hydrolytic stability}

Hydrolytic stability is a crucial factor for practical applications of photochromic compounds in humid environments or aqueous biological systems and thus 

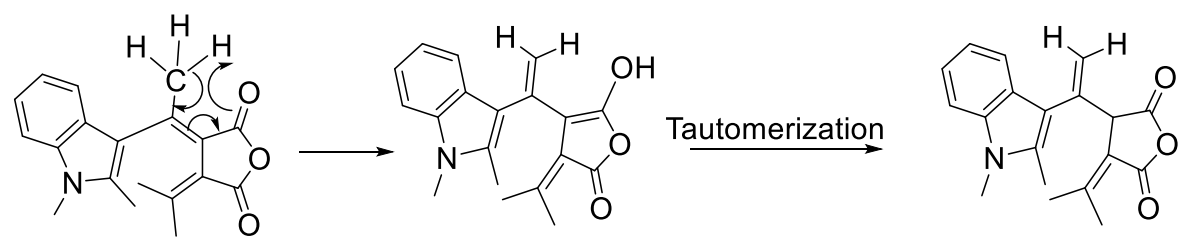

Non photochromic material

Figure 11. Proposed mechanism of 1,5 sigmatropic rearrangement and tautomerization.

fulgimides are the most suitable fulgide derivative. ${ }^{55,56}$ Fulgides are unstable in hydrolytic media because of their succinic anhydride ring, while fulgimides with a succinimide ring have improved hydrolytic stability ${ }^{24}$. Lees et al. ${ }^{17}$ compare the hydrolytic stability of fulgides and fulgimides. When indolylfulgides were dissolved in a 70:30 (ethanol:water) mixture at room temperature, the fluorinated indolylfulgides showed a significant loss in absorbance. In contrast, indolylfulgimides were more resistant to hydrolysis. In general, the $Z$ form of indolylfulgimides maintained at least $90 \%$ absorbance at $\lambda_{\max }$ after $360 \mathrm{~h}$ in the ethanol and water mixture. Slow $C$ to $Z$ isomerization of the $C$ form make the measurement of the hydrolytic stability of the $C$ form complicated. However, the fulgimides kept $55 \%$ of their original absorbance at the $C$ form $\lambda_{\max }$ after 2 weeks in a 70:30 (ethanol:water) mixture at room temperature. ${ }^{17}$

Fulgimides maintained photochromic activity in aqueous mixtures, such as 1:1 (ethanol:water). The $Z, E$ and $C$ forms of a fulgimide synthesized by Matsushima et al. kept their photochromic properties in aqueous mixtures, Figure 12. Photochemical reversibility of this fulgimide was examined without substantial solvolysis in $1: 1$ aqueous ethanol solution. ${ }^{44}$ 


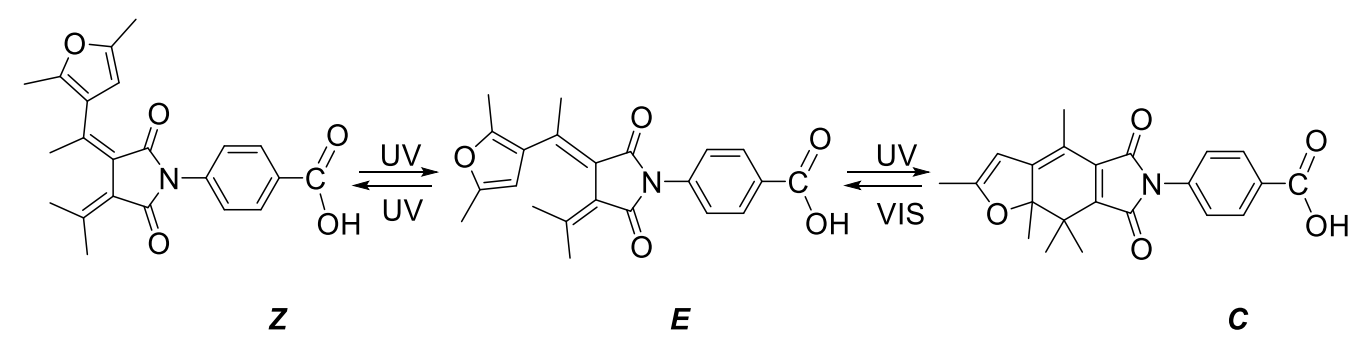

Figure 12. Hydrolytically stable fulgimide synthesized by Matsushima et al.

\subsubsection{Application of photochromic fulgimides}

Photochromic fulgimides have been applied in several areas, for example regulating energy transfer with light and for $2 \mathrm{D}$ molecular memories. Port et al. ${ }^{57,58}$ found that energy transfer could be regulated photochemically after synthesizing a molecule in which intramolecular energy transfer was dependent upon the form of the photochromic fulgimide. A covalently attached photochromic indolylfulgimide was sandwiched between an anthracene, donor group, and coumarin, acceptor group, in a photoswitchable donor-switch-acceptor energy transfer system, Figure 13.

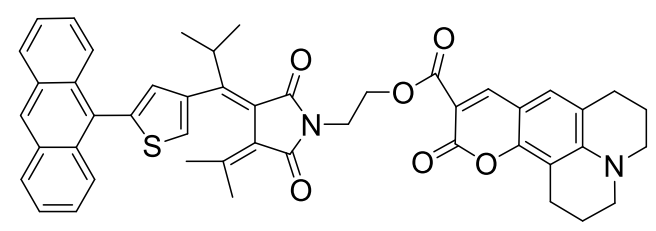

Figure 13. Photoswitchable energy transfer compound containing a fulgimide.

The rate of access to stored information is very important in 2D molecular memories, and depends on the rate of photochromic isomerization from the closed to the open forms and the dye fluorescence lifetime. Fulgimide architecture for $2 \mathrm{D}$ molecular memories was introduced by Rentizepis et al. ${ }^{59}$. A photochromic fulgimide linked with a strongly fluorescing oxazine dye was used to access the stored information in 2D molecular memories, Figure 14. 


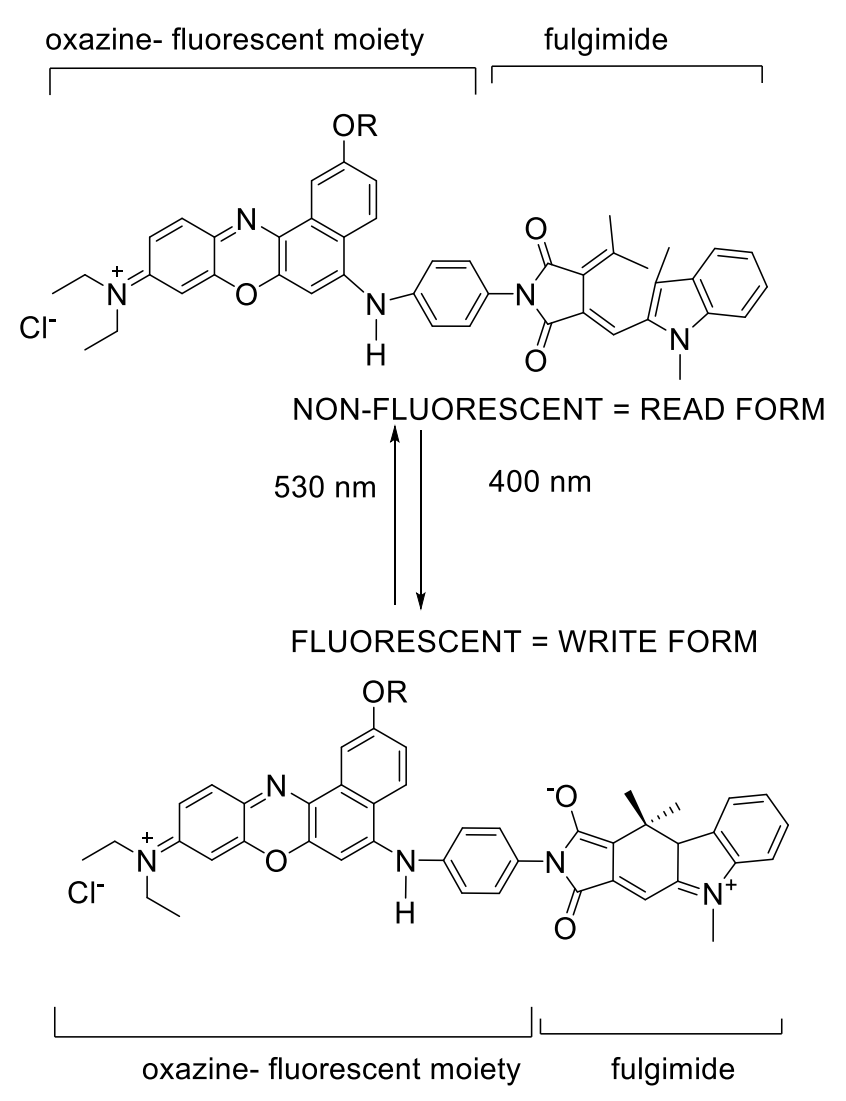

Figure 14. Molecular memory by Rentzepis.

Moore et al. ${ }^{60}$ reported that photochromic fulgimide can perform sophisticated logic operations. A complex system in which the photochromes were covalently linked together in a single molecular device was developed. The output of the one molecular switch was transmitted to the other chromophore by photoinduced isomerization. The dyad of porphyrin-fulgimide (P-FG) is an example of this molecular device, Figure 15.

\section{OBJECTIVES OF RESEARCH}

The overall aim of this research is to synthesize, purify and characterize a photochromic copolymer. The selected $\mathrm{N}$-alkylindolylfulgimide containing copolymer is expected to have improved thermal and hydrolytic stability relative to 
an $\mathrm{N}$-arylindolylfulgimide. Kanaoka et al. ${ }^{61}$ reported that $\mathrm{N}$-ethylmaleimide $(\mathrm{N}$ alkylimide) is 25 times more stable than $N$-phenylmaleimide ( $N$-arylimide) in a phosphate buffer at $\mathrm{pH} 7.0$.

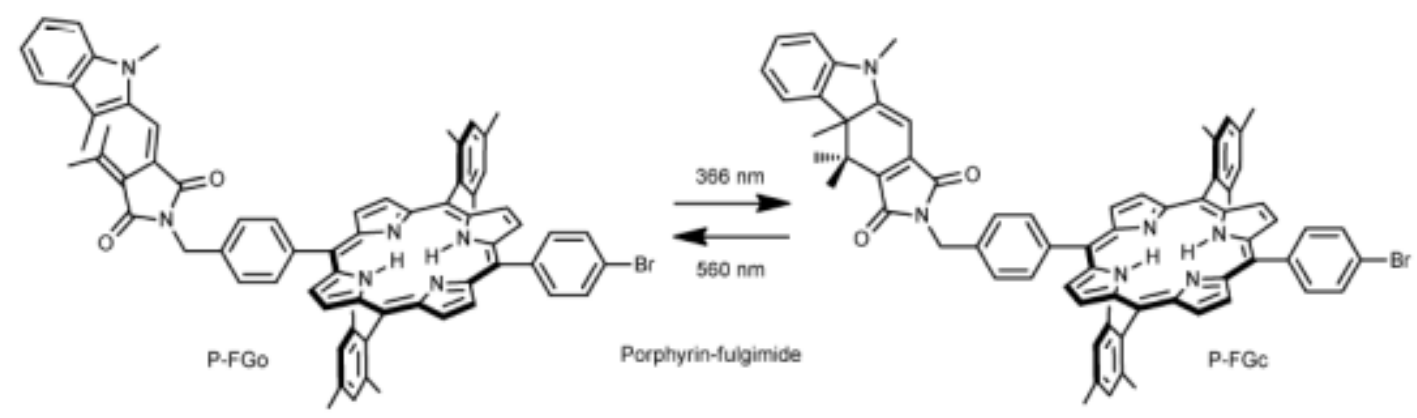

Figure 15. Molecular device of porphyrin-fulgimide dyad .60

\subsection{Synthesis of a polymerizable photochromic fulgimide monomer}

A photochromic monomer $N$-alkylindolylfulgimide 1 was synthesized with polymerizable vinylbenzyl group attached on the nitrogen atom of the imide ring.

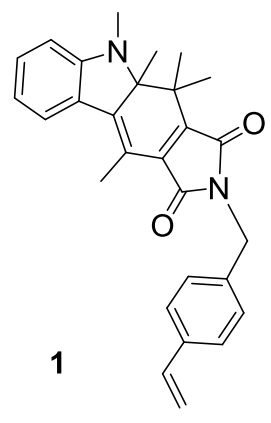

\subsection{Synthesis of a linear fulgimide 1-co-PAA copolymer.}

Photochromic monomer $\mathrm{N}$-alkylindolylfulgimide 1 was copolymerized with acrylamide (AA) providing a linear copolymer. The $\mathrm{N}$-alkylindolylfulgimide linear copolymer was synthesized to improve the thermal stability of the $C$ form relative to the previously prepared $\mathrm{N}$-arylindolylfulgimide linear copolymer. 


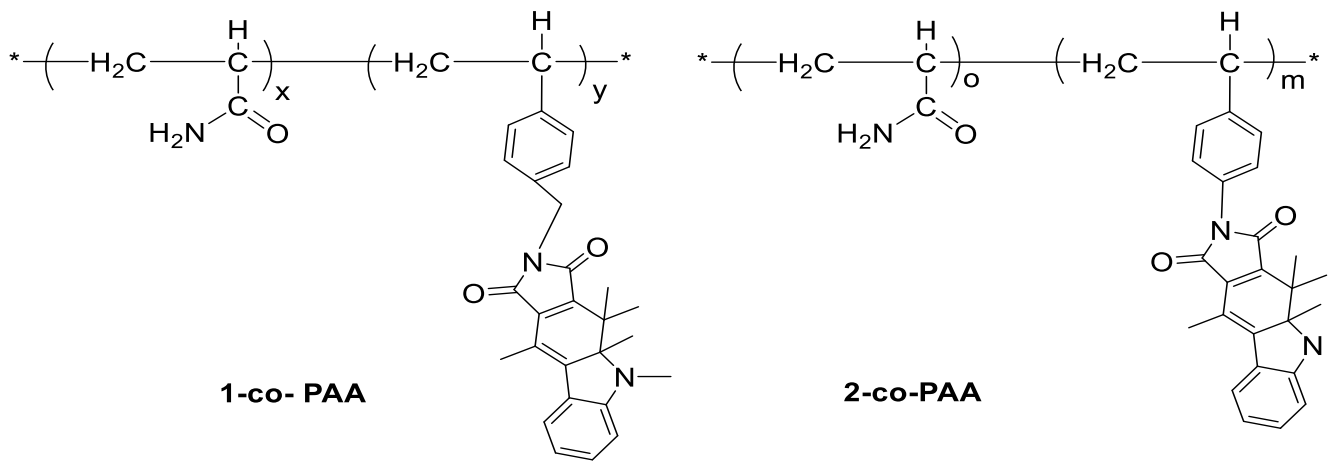

\subsection{Characterization}

Photochromic fulgimide 1 and its copolymer 1-co-PAA were characterized by measuring UV-Vis spectra, and thermal and photochemical stability.

\section{EXPERIMENTAL AND PROCEDURE}

\subsection{General Remarks}

All commercially available materials were used without further purification. Compounds were purified by flash chromatography using 230-400 mesh silica gel. A Cary 300 spectrophotometer was used to record UV-Vis spectra. A Bruker $400 \mathrm{MHz}$ NMR spectrometer was used to record NMR spectra. The ${ }^{1} \mathrm{H}$ and ${ }^{13} \mathrm{C}$ NMR samples were internally referenced to TMS or residual solvent. Photochemical stability was measured with an Oriel $1000 \mathrm{~W} \mathrm{Hg}(\mathrm{Xe})$ arc lamp as the light source. A band pass filter was used for $365 \mathrm{~nm}$ light and a cut off filter was used for $>515 \mathrm{~nm}$ light.

\subsection{Synthesis of $\mathbf{N}$-alkylindolylfulgimide}

\subsubsection{Synthesis of dimethyl isopropylidenesuccinate}




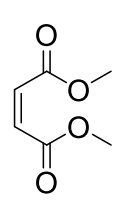

3

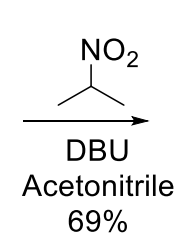

$69 \%$

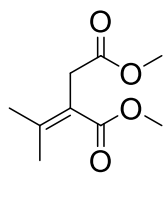

4

The 2-Nitropropane $(76.60 \mathrm{~g}, 0.860 \mathrm{~mol})$ was dissolved in $2.4 \mathrm{~L}$ of acetonitrile, followed by addition of dimethyl maleate $3(135.70 \mathrm{~g}, 0.942 \mathrm{~mol})$ and 1,8Diazobicyclo[5.4.0]undec-7-ene (DBU) $(201.56 \mathrm{~g}, 1.32 \mathrm{~mol})$. The reaction mixture was left to react for $16 \mathrm{~h}$ at room temperature and then concentrated in vacuo. The residue was quenched with $600 \mathrm{~mL}$ of $\mathrm{HCl}$. The mixture was extracted with $1.5 \mathrm{~L}$ of ethyl acetate and washed twice with $600 \mathrm{~mL}$ of water $(2 \times 600 \mathrm{~mL})$. The organic layer was dried over $\mathrm{MgSO}_{4}$, filtered and concentrated in vacuo. The crude product was purified by vacuum distillation to yield $128.48 \mathrm{~g}(73 \%)$ of dimethyl isopropylidenesuccinate $4 .{ }^{1} \mathrm{H} \mathrm{NMR}\left(\mathrm{CDCl}_{3}, 400 \mathrm{MHz}\right) \delta 3.66(\mathrm{~s}, 3 \mathrm{H}), 3.61(\mathrm{~s}, 3 \mathrm{H})$, $3.47(\mathrm{~s}, 2 \mathrm{H}), 2.23(\mathrm{~s}, 3 \mathrm{H}), 1.83(\mathrm{~s}, 3 \mathrm{H})$.

\subsubsection{Synthesis of 1,2-dimethylindole}

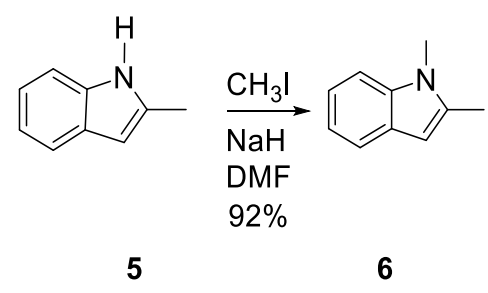

The 2-Methylindole $5(15.40 \mathrm{~g}, 0.117 \mathrm{~mol})$ was dissolved in $200 \mathrm{~mL}$ of dimethylformamide (DMF) and left to react at room temperature for $30 \mathrm{~min}$. The mixture was then cooled to $0{ }^{\circ} \mathrm{C}$ followed by addition of $\mathrm{NaH}(6.01 \mathrm{~g}$ of $60 \%$ dispersed in oil, $0.150 \mathrm{~mol}$ ) and left to react for $10 \mathrm{~min}$. After $10 \mathrm{~min}$, methyliodide 
$(8.0 \mathrm{~mL}, 0.129 \mathrm{~mol})$ was added. The reaction mixture was left to react under argon gas at room temperature for $5 \mathrm{~h}$. The mixture was then concentrated in vacuo. The concentrated residue was dissolved in ethyl acetate $500 \mathrm{~mL}$ and extracted with water $(3 \times 200 \mathrm{~mL})$ and brine $(1 \times 200 \mathrm{~mL})$. The organic layer was dried over $\mathrm{MgSO}_{4}$ and concentrated in vacuo. The product, 1,2-dimethylindole 6, was obtained in $92 \%$ yield $(15.65 \mathrm{~g}) .{ }^{1} \mathrm{H}$ NMR $\left(\mathrm{CDCl}_{3}, 400 \mathrm{MHz}\right) \delta 7.50(\mathrm{~d}, J=7.4 \mathrm{~Hz})$, $7.37(\mathrm{~d}, J=7.9 \mathrm{~Hz}, 1 \mathrm{H}), 7.17(\mathrm{t}, J=7.4 \mathrm{~Hz}, 1 \mathrm{H}), 7.07(\mathrm{t}, J=7.1 \mathrm{~Hz}, 1 \mathrm{H}), 6.22(\mathrm{~s}$, 1H), $3.73(\mathrm{~s}, 3 \mathrm{H}), 2.48(\mathrm{~s}, 3 \mathrm{H})$.

\subsubsection{Synthesis of 3-acetyl-1,2-dimethylindole}

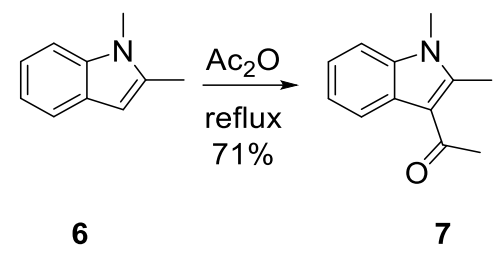

The 1,2-dimethylindole $6(9.50 \mathrm{~g}, 65.4 \mathrm{~mol})$ was dissolved in $160 \mathrm{~mL}$ of acetic anhydride (170 g, $1.7 \mathrm{~mol})$. The reaction mixture was reflux under argon for $36 \mathrm{~h}$. The reaction mixture was concentrated in vacuo and the residue was recrystallized from hexanes $/ \mathrm{CH}_{2} \mathrm{Cl}_{2}$. The product, 3-acetyl-1,2-dimethylindole 7, was obtained in $71 \%$ yield $(6.75 \mathrm{~g}) .{ }^{1} \mathrm{H}$ NMR $\left(\mathrm{CDCl}_{3}, 400 \mathrm{MHz}\right) \delta 7.95(\mathrm{~d}, J=7.1 \mathrm{~Hz}, 1 \mathrm{H}), 7.35(\mathrm{t}$, $J=7.4 \mathrm{~Hz}, 1 \mathrm{H}), 7.34(\mathrm{t}, J=7.4 \mathrm{~Hz}, 1 \mathrm{H}), 7.28(\mathrm{~d}, J=7.9 \mathrm{~Hz}, 1 \mathrm{H}), 3.72(\mathrm{~s}, 3 \mathrm{H}), 2.80$ $(\mathrm{s}, 3 \mathrm{H}), 2.70(\mathrm{~s}, 3 \mathrm{H})$. 


\subsubsection{Synthesis of Cis/trans indolelactones}

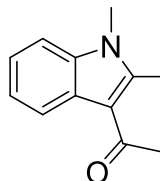

7

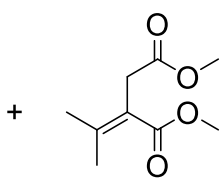

4

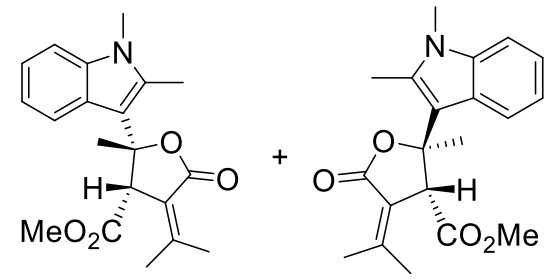

Cis-8

Trans-8

Dimethyl isopropyliedenesuccinate $4(23.9 \mathrm{~g}, 128.35 \mathrm{mmol})$ was dissolved in $60 \mathrm{~mL}$ of dry hexanes and cooled to $-78^{\circ} \mathrm{C}$. Lithium diisopropylamide (LDA) (76 $\mathrm{mL}$ of a $2 \mathrm{M}$ solution in THF, $152 \mathrm{mmol}$ ) was transferred to an additional funnel via a cannula. The LDA was added dropwise to the reaction mixture, and the reaction mixture was left to react for $30 \mathrm{~min}$ at $-78{ }^{\circ} \mathrm{C}$ under argon. The 3-acetyl-1,2dimethylindole $7(7.01 \mathrm{~g}, 38.8 \mathrm{mmol})$ was dissolved in $200 \mathrm{~mL}$ of dry hexanes. The solution of 3-acetyl-1,2-dimethylindole was added dropwise to the reaction mixture of LDA and dimethyl isopropylidenesuccinate 4 . The reaction mixture was left to react at room temperature for $2 \mathrm{~d}$. The solution was concentrated in vacuo and the residue was dissolved with $200 \mathrm{~mL}$ of water and acidified with $5 \% \mathrm{H}_{2} \mathrm{SO}_{4}$ to $\mathrm{pH} 2$. The aqueous layer was extracted with ethyl acetate $(3 \times 100 \mathrm{~mL})$. The organic layer was washed with brine $(2 \times 100 \mathrm{~mL})$, dried over $\mathrm{MgSO}_{4}$, filtered, and concentrated in vacuo. The crude product was purified by flash chromatography (2:1 hexanes/ethyl acetate) and the resulting mixture of cis/trans indolelactones 8 was obtained in $21 \%$ yield $(2.28 \mathrm{~g})$. Mixture of cis and trans lactones was separated during column chromatography by collecting different fraction. Trans lactone: ${ }^{1} \mathrm{H}$ $\operatorname{NMR}\left(\mathrm{CDCl}_{3}, 400 \mathrm{MHz}\right) \delta 7.81(\mathrm{~d}, J=7.81 \mathrm{H}), 7.29-7.27(\mathrm{~m}, 1 \mathrm{H}), 7.20(\mathrm{td}, J=7.0$, $1.1 \mathrm{~Hz}, 1 \mathrm{H}), 7.15(\mathrm{td}, J=7.4,1.5 \mathrm{~Hz}, 1 \mathrm{H}), 4.47(\mathrm{~s}, 1 \mathrm{H}), 3.85(\mathrm{~s}, 3 \mathrm{H}), 3.63(\mathrm{~s}, 3 \mathrm{H})$, 
$2.56(\mathrm{~s}, 3 \mathrm{H}), 2.25(\mathrm{~s}, 3 \mathrm{H}), 1.80(\mathrm{~s}, 3 \mathrm{H}), 1.70(\mathrm{~s}, 3 \mathrm{H})$. Cis lactone: ${ }^{1} \mathrm{H}$ NMR $\left(\mathrm{CDCl}_{3}\right.$, $400 \mathrm{MHz}) \delta 8.14(\mathrm{~d}, J=7.8 \mathrm{~Hz}, 0.3 \mathrm{H}), 7.52(\mathrm{~d}, J=7.8 \mathrm{~Hz}, 0.7 \mathrm{H}), 7.23-7.17(\mathrm{~m}$, $1 \mathrm{H}), 7.13(\mathrm{t}, J=7.8 \mathrm{~Hz}, 1 \mathrm{H}), 7.06(\mathrm{t}, J=7.1 \mathrm{~Hz}, 1 \mathrm{H}), 4.27(\mathrm{~s}, 0.7 \mathrm{H}), 4.11(\mathrm{~s}, 0.3 \mathrm{H})$, $3.63(\mathrm{~s}, 3 \mathrm{H}), 3.01(\mathrm{~s}, 2 \mathrm{H}), 2.87(\mathrm{~s}, 1 \mathrm{H}), 2.58(\mathrm{~s}, 2 \mathrm{H}), 2.43(\mathrm{~s}, 1 \mathrm{H}), 2.37(\mathrm{~s}, 3 \mathrm{H}), 1.96$ (s, 3H), $1.88(\mathrm{~s}, 2 \mathrm{H}), 1.78(\mathrm{~s}, 1 \mathrm{H})$.

\subsubsection{Synthesis of methylindolylfulgide}

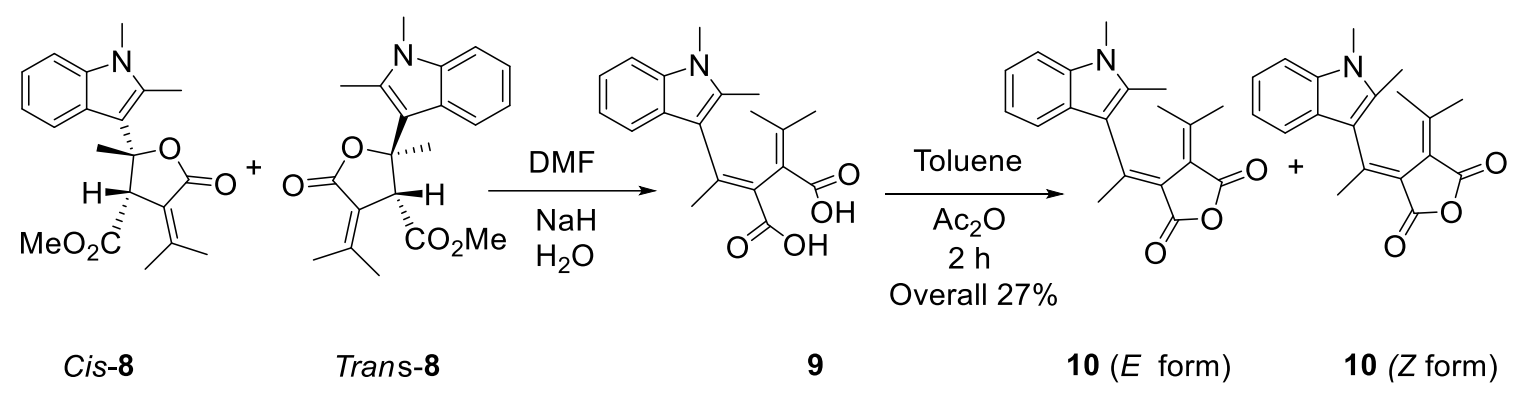

Cis/trans indolelactones $8(2.90 \mathrm{~g}, 8.50 \mathrm{mmol})$ was dissolved in $250 \mathrm{~mL}$ of DMF at $0{ }^{\circ} \mathrm{C}$. Sodium hydride (60\% dispersion in oil, $\left.0.84 \mathrm{~g}, 21 \mathrm{mmol}\right)$ was added to the solution of cis/trans indolelactones 8 . The reaction mixture was warmed to room temperature and left to react for $1 \mathrm{~h}$. Then, the reaction mixture was cooled back to $0{ }^{\circ} \mathrm{C}$. After cooling, water $(2.5 \mathrm{~mL}, 139 \mathrm{mmol})$ was added. Then the reaction mixture was stirred overnight and concentrated in vacuo. The residue was dissolved in $150 \mathrm{~mL}$ of water and washed with ethyl acetate $(3 \times 100 \mathrm{~mL})$. The aqueous layer was acidified with $10 \% \mathrm{HCl}$ to $\mathrm{pH} 2$ and the mixture was extracted with ethyl acetate $(3 \times 100 \mathrm{~mL})$. The combined organic layers were dried over $\mathrm{MgSO}_{4}$, filtered, and concentrated in vacuo to obtain the crude diacid intermediate 9. The intermediate diacid 9 was dissolved in $100 \mathrm{~mL}$ of toluene, followed by the addition of acetic anhydride (50 mL, $0.53 \mathrm{~mol})$. The reaction mixture was heated to reflux for $2 \mathrm{~h}$ under argon and then concentrated in vacuo. The residue was 
dissolved in water $(200 \mathrm{~mL})$ and extracted with $\mathrm{CH}_{2} \mathrm{Cl}_{2}(3 \times 100 \mathrm{~mL})$. The combined organic layers were dried over $\mathrm{MgSO}_{4}$, filtered, and concentrated in vacuo. The crude product was purified by column chromatography with $\mathrm{CH}_{2} \mathrm{Cl}_{2}$ and recrystallized from $\mathrm{CH}_{2} \mathrm{Cl}_{2} /$ hexanes to obtain $0.78 \mathrm{~g}(27 \%)$ of methylindolylfulgide.

${ }^{1} \mathrm{H} \mathrm{NMR}\left(\mathrm{CDCl}_{3}, 400 \mathrm{MHz}\right) \delta 7.40(\mathrm{~d}, J=7.9 \mathrm{~Hz}, 1 \mathrm{H}), 7.30(\mathrm{~d}, J=8.7 \mathrm{~Hz}, 1 \mathrm{H})$, 7.26-7.24 (m, 1H), $7.15(\mathrm{td}, J=7.3,1.1 \mathrm{~Hz}, 1 \mathrm{H}), 3.69(\mathrm{~s}, 3 \mathrm{H}), 2.81(\mathrm{~s}, 3 \mathrm{H}), 2.20(\mathrm{~s}$, $6 \mathrm{H}), 0.94(\mathrm{~s}, 3 \mathrm{H})$.

\subsubsection{Synthesis of indolylfulgimide}

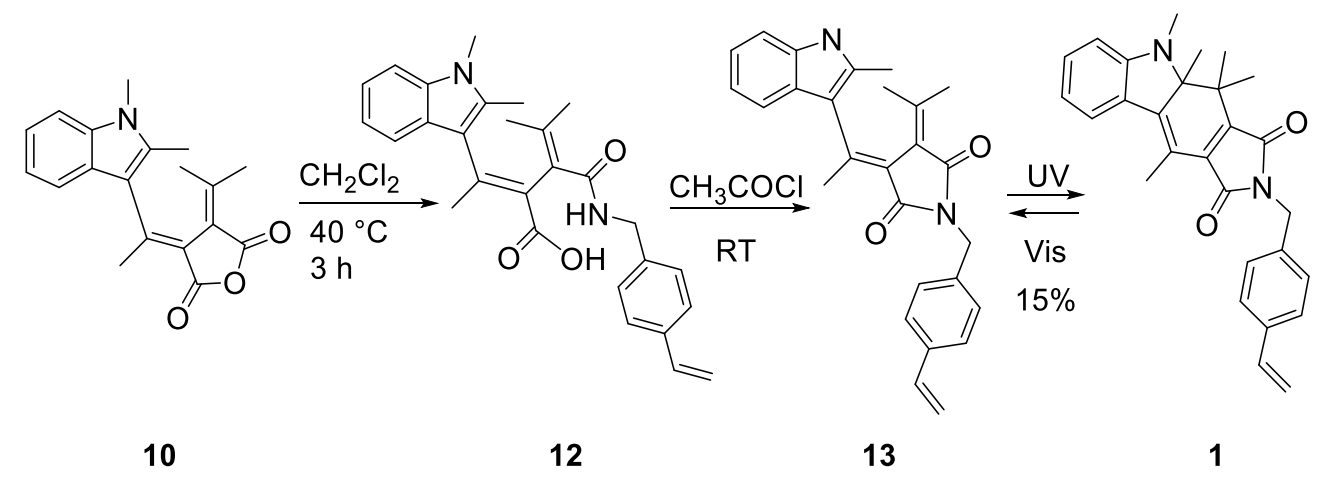

Methylindolylfulgide $10(0.050 \mathrm{~g}, 0.16 \mathrm{mmol})$ and vinylbenzylamine 11 (0.032 $\mathrm{g}, 0.24 \mathrm{mmol}$ ) were dissolved in $3.2 \mathrm{~mL}$ of $\mathrm{CH}_{2} \mathrm{Cl}_{2}$, and left to react at $40{ }^{\circ} \mathrm{C}$ for 3 h. After solvent evaporation, $3.2 \mathrm{~mL}$ of acetyl chloride was added to the succinamic acid 12 and left to react for $1 \mathrm{~h}$ at room temperature. The mixture was concentrated in vacuo. The residue was neutralized with saturated $\mathrm{NaHCO}_{3}$ over ice $(10 \mathrm{~mL})$. The crude product was extracted with $\mathrm{CH}_{2} \mathrm{Cl}_{2}(3 \times 15 \mathrm{~mL})$. The combined organic layers were dried over $\mathrm{MgSO}_{4}$ and concentrated in vacuo. The crude product was purified by column chromatography (1:1 hexanes/ethyl acetate) to obtain a mixture 
of $E / Z$ isomers of $N$-alkylindolylfulgimde 1 . The mixture of isomers was dissolved in toluene $(4 \mathrm{~mL})$ and illuminated with $365 \mathrm{~nm}$ light to obtain the closed $C$ form. Purification by column chromatography $\left(1: 1\right.$ hexanes $\left./ \mathrm{CH}_{2} \mathrm{Cl}_{2}\right)$ yielded $0.010 \mathrm{~g}$ (15\%) of $\mathrm{N}$-alkylindolylfulgimide 1C. $C$ form: ${ }^{1} \mathrm{H} \mathrm{NMR}\left(\mathrm{CDCl}_{3}, 400 \mathrm{MHz}\right) \delta 7.55(\mathrm{~d}$, $J=7.9 \mathrm{~Hz}, 1 \mathrm{H}), 7.35(\mathrm{~m}, 2 \mathrm{H}), 7.20(\mathrm{t}, J=7.9 \mathrm{~Hz}, 1 \mathrm{H}), 6.69(\mathrm{~m}, 4 \mathrm{H}), 6.53(\mathrm{~d}, J=$ $8.9 \mathrm{~Hz}, 1 \mathrm{H}), 5.72(\mathrm{~d}, J=18.1 \mathrm{~Hz}, 1 \mathrm{H}), 5.22(\mathrm{~d}, J=10.9 \mathrm{~Hz}, 1 \mathrm{H}), 4.61(\mathrm{~s}, 2 \mathrm{H}), 2.87$ (s, 3H), $2.40(\mathrm{~s}, 3 \mathrm{H}), 1.74(\mathrm{~s}, 3 \mathrm{H}), 1.24(\mathrm{~s}, 3 \mathrm{H}), 1.15(\mathrm{~s}, 3 \mathrm{H})$.

\subsubsection{Preparation of linear copolymer 1-co-PAA}
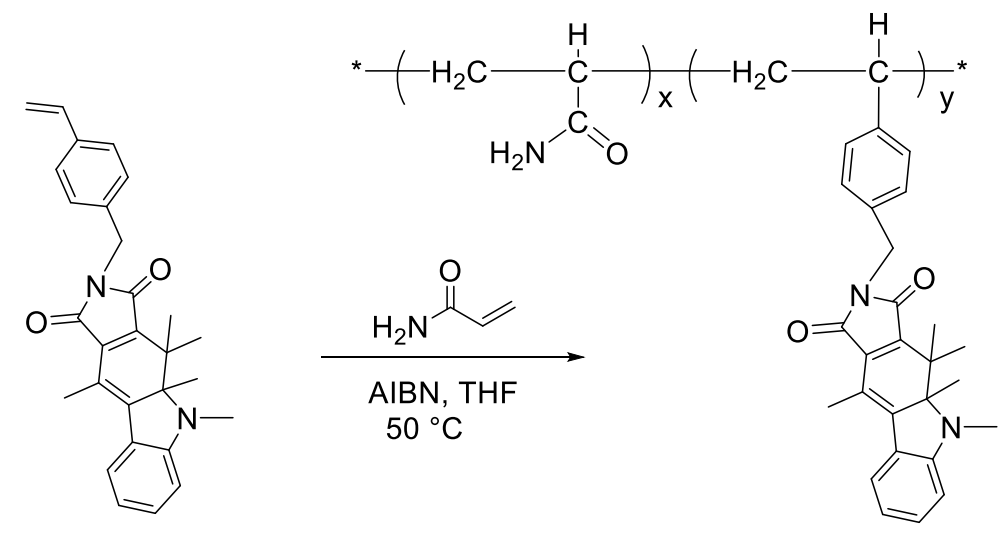

The $C$ form of $N$-alkylindolylfulgimide $1 \mathrm{C}(4.5 \mathrm{mg}, 0.010 \mathrm{mmol})$ was dissolved in $2 \mathrm{~mL}$ of THF. With stirring, acrylamide (0.35 g, $4.9 \mathrm{mmol})$ and azobisisobutyronitrile (AIBN) (1\% of acrylamide) were added to the solution. The mixture was sealed in a glass ampoule under vacuum and kept at $50{ }^{\circ} \mathrm{C}$ for $48 \mathrm{~h}$. After $48 \mathrm{~h}$, a violet polymeric gel was formed. The polymeric gel was dissolved in $30 \mathrm{~mL}$ of nanopure water and then transferred to a dialysis bag (M.W. cutoff: 60008000). Dialysis was performed 4 times in $3.5 \mathrm{~L}$ of water. The copolymer solution was dried in vacuo to provide the $C$-form copolymer 1-co-PAA. 


\subsection{Characterization}

\subsubsection{Spectral determination}

A concentrated stock solution of the $C$ form of $N$-alkylindolylfulgimide $1 \mathrm{C}$ in toluene $(25 \mathrm{~mL})$ was prepared from $10 \mathrm{mg}$ of purified solid sample. A freshly prepared stock solution was diluted with toluene $(10 \mathrm{~mL})$ to make five dilute solutions ranging from 0.20 to $0.50 \mathrm{mM}$. Absorbance of each sample was recorded by a UV-Vis spectrophotometer. The extinction coefficient of the $C$ form was determined from the slope of a plot of absorbance vs concentration. The five diluted solutions of the $C$ form were irradiated with visible light $>515 \mathrm{~nm}$ light to quantitatively convert the $C$ form to the $E$ form. Absorbance of each sample was recorded by a UV-Vis spectrophotometer. The extinction coefficient of the $E$ form was determined.

\subsubsection{Thermal and hydrolytic stability}

Monomer based study: The thermal stability of the $N$-alky/indolylfulgimide 1 monomer was measured by a UV-Vis spectrophotometer. A solutions of the $C$ form was prepared in toluene $(10 \mathrm{ml})$ with an absorbance of 0.54 at $\lambda \max$ of the $C$ form. Each of 7 ampoules were filled with $1.2 \mathrm{ml}$ of $C$ form solution and sealed. The ampoules were then wrapped in aluminum foil and incubated in a water bath maintained at $80^{\circ} \mathrm{C}$. Ampoules were removed at specific time and opened and UV Vis absorbance was determined. Same procedure was repeated except that a stock solution of the $C$ form was irradiated with visible light to produce the $E$ form

prior to being transferred to ampoules. A freshly prepared solution of $C$ form and 
corresponding copolymer was irradiated with visible light with cut off filter $>515$ $\mathrm{nm}$ to obtained the $E$ form.

Copolymer based study: The hydrolytic stability of the copolymer 1-co PAA in $50 \mathrm{mM}$ sodium phosphate buffer $(\mathrm{pH} 7.4)$ and $50 \mathrm{mM}$ sodium acetate buffer $(\mathrm{pH}$ 5.0) were measured by a UV-Vis spectrophotometer. A solution of the $C$ form was prepared in buffer $(10 \mathrm{ml})$ with an absorbance of 0.57 at $\lambda_{\max }$ of the $C$ form. Each of 7 ampoules were filled with $1.2 \mathrm{ml}$ of $C$ form solution and sealed. The ampoules were then wrapped in aluminum foil and incubated in a water bath maintained at $37^{\circ} \mathrm{C}$. The Same procedure was repeated except that a stock solution of the $C$ form was irradiated with visible light to produce the $E$ form prior to being transferred to ampoules. Ampoules were removed at specific time and opened and UV Vis absorbance was measured.

\subsubsection{Photochemical stability}

To measure the photochemical stability of $\mathrm{N}$-alkylindolylfulgimide $\mathbf{1}$ and its copolymer, $C$ form monomer of compound 1 in toluene and the $C$ form of copolymer in $50 \mathrm{mM}$ sodium phosphate buffer ( $\mathrm{pH} 7.4)$ and $50 \mathrm{mM}$ sodium acetate buffer ( $\mathrm{pH} 5.0$ ) were quantitatively converted to solutions of $E$ form by irradiating with visible light $>515 \mathrm{~nm}$. The initial absorbance of the $E$ form solutions was 0.91 at $\lambda_{\max }$. The $E$ form solution was irradiated to the photostationary state (PSS) with $365 \mathrm{~nm}$ light for monomer and $375 \mathrm{~nm}$ light for 1-co-PAA. The UV-Vis spectrophotometer was used to determine the absorbance at $\lambda_{\max }$ of the $C$ forms in the visible region. The time taken to achieve $90 \%$ of the coloration reaction ( $E$ to $C$ form) at $\lambda_{\max }$ of PSS was then measured. Then, the transformation time of 
decoloration reaction of $C$ form solutions to $E$ form solution was measured. The same solutions of $C$ form at PSS were then irradiated with visible light $>515 \mathrm{~nm}$ again until the absorbance at $\lambda_{\max }$ of the $C$-form, solutions were $<1 \%$. Once, the duration of the coloration and decoloration were established, the freshly prepared solutions were converted back and forth with an automated filter switch. All the solutions were stirred and capped during reaction to avoid evaporation of the solvents. After a designated number of irradiation cycles, the samples were fully converted to PSS with prolonged irradiation and the absorbance was recorded with a UV-Vis spectrophotometer. The photochemical stability was determined by comparison with the initial absorbance at the PSS of $C$.

\section{RESULTS AND DISCUSSION}

\subsection{Synthesis of $N$-alkylindolylfulgimide 1}
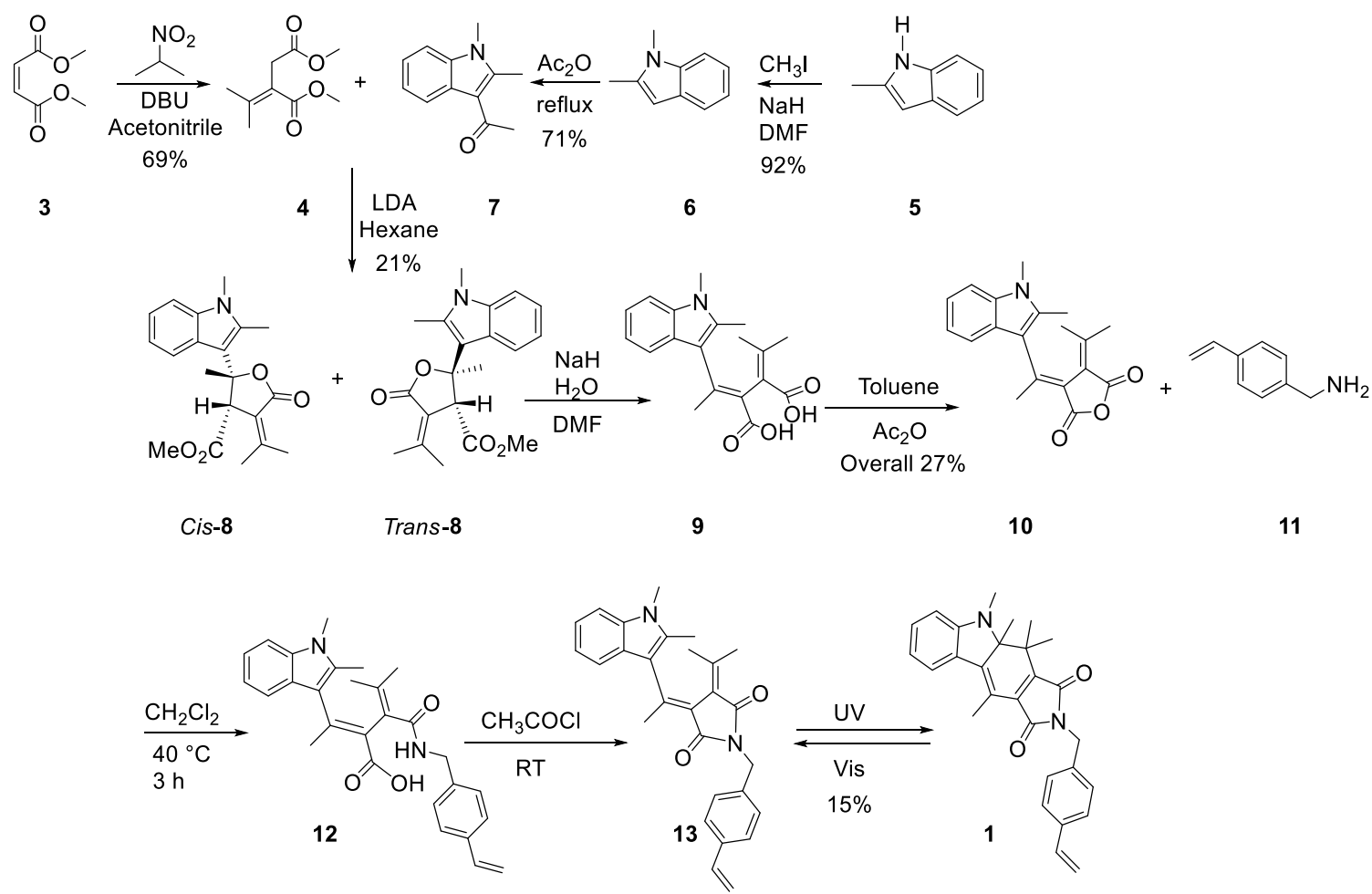
A new $\mathrm{N}$-alkylindolylfulgimide $\mathbf{1}$, with a vinybenzyl attached on the succinimde ring, was synthesized from the precursor indolylfulgide $\mathbf{1 0}$. Indolylfulgide 10, was synthesized from commercially available 2-methylindole 5 . After methylation of 2methylindole 5 and subsequent acetylation of 1,2-dimethylindole 6 the product 1,2dimethyl-3-acetylindole $\mathbf{7}$ was obtained. Dimethyl isopropylidenesuccinate $\mathbf{4}$ was reacted with indole 7 to yield cis/trans indolelactones $\mathbf{8}$ via a Stobbe condensation. The indolelactones 8 were then hydrolyzed to a dicarboxylic acid 9 by using $\mathrm{NaH}$ and then water. After completion of the reaction the dicarboxylic acid $\mathbf{9}$ was dehydrated in refluxing acetic anhydride to obtain methyl indolylfulgide 10 in $27 \%$ yield. Indolylfulgide $\mathbf{1 0}$ was then used as a starting material for the synthesis of $\mathrm{N}$ alkylindolylfulgimide $\mathbf{1}$. The anhydride ring of methylindolylfulgide $\mathbf{1 0}$ was opened via addition of vinylbenzylamine $\mathbf{1 1}$. The resulting succinamic acid $\mathbf{1 2}$ was then dehydrated in acetyl chloride to yield the open form $\mathrm{N}$-alkylindolylfulgimide $1 \mathrm{E}$. The $\mathrm{N}$-alkylindolylfulgimide 1E was irradiated with UV light to obtain the closed form of $\mathrm{N}$-alkylindolylfulgimide $\mathbf{1 C}$. The linear copolymer 1-co-PAA was synthesized from $\mathrm{N}$-alkylindolylfulgimide 1C and acrylamide via free-radical polymerization with AIBN as the initiator. The linear copolymer was photochromic and soluble in water.
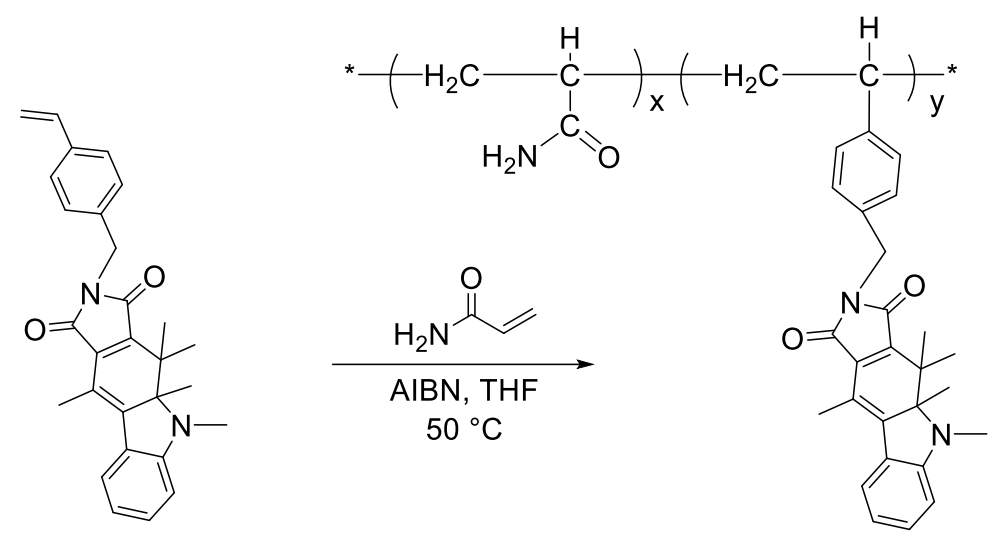


\subsection{Characterization}

\subsubsection{UV-Vis absorption spectra}

The UV-Vis absorption spectra of $C$ and $E$ forms of $N$-alkylindolylfulgimide 1 in toluene, and 1-co-PAA in phosphate and acetate buffer were determined, Table 1. After copolymerization, the resulting copolymer displayed a similar UV-Vis absorption spectrum as the corresponding monomer. In phosphate buffer, the $\lambda_{\max }$ of the 1-co-PAA, $C$ and $E$ forms, exhibited a 17 and $7 \mathrm{~nm}$ bathochromic shift relative to the fulgimide 1 monomer in toluene, respectively. It has been proposed

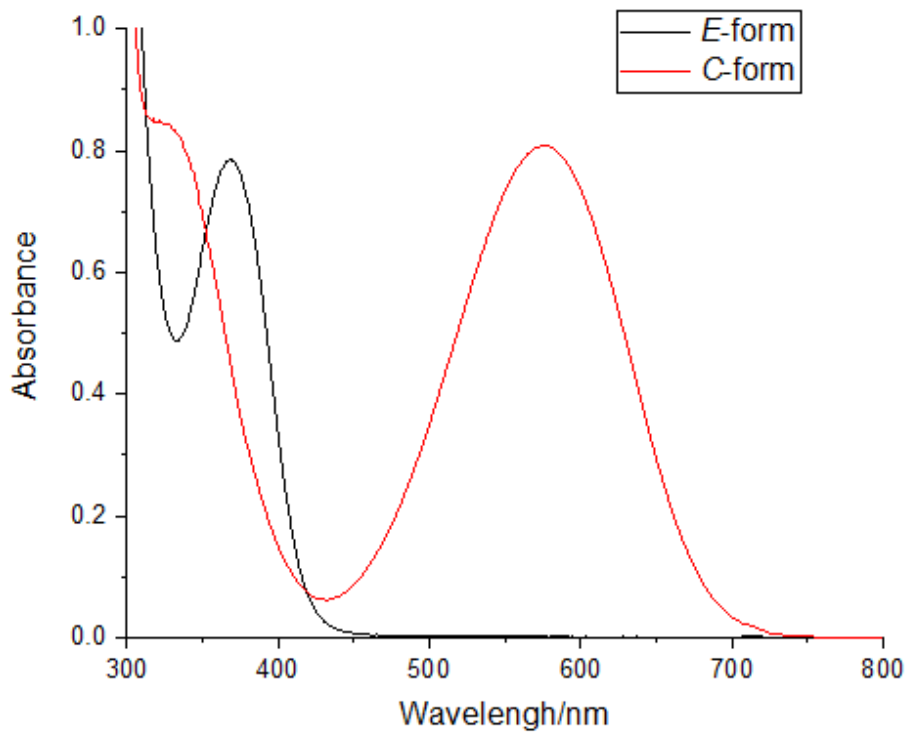

Figure 16. UV-Vis absorption spectra of $\mathrm{N}$ - alkylindolylfulgimide 1 in toluene. 


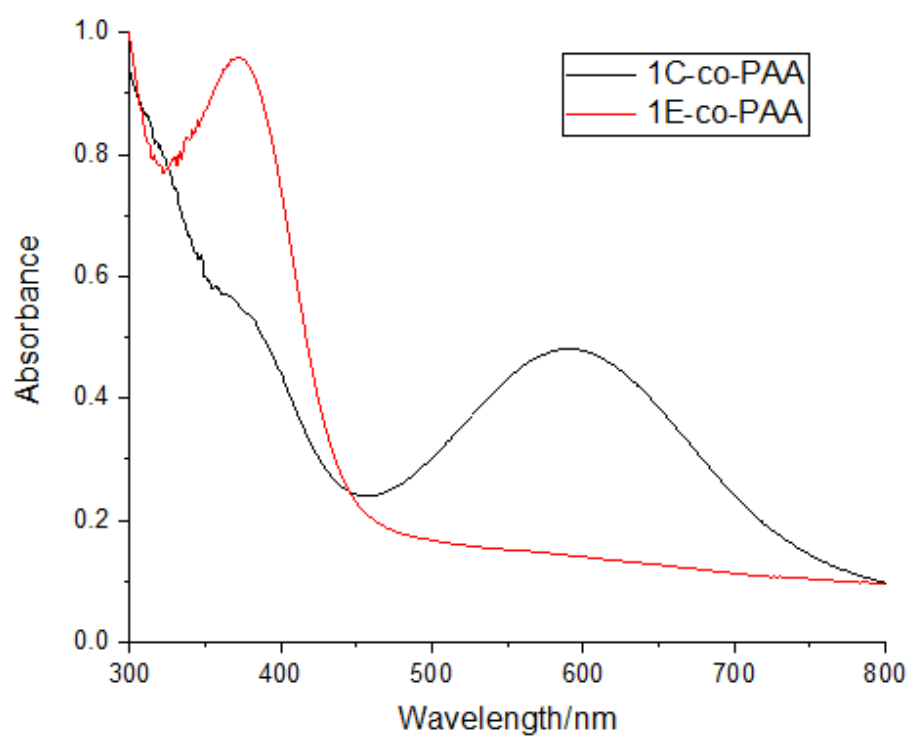

Figure 17. UV-Vis absorption spectra of 1-co-PAA in buffer.

that the $C$ form has a near planar structure which can establish an extended conjugated system. The charge separated $C$ form has strong interactions with protic solvents causing a decrease in the energy of the electronic transitions that results in a shift of the absorption band to longer wavelength. ${ }^{12,66}$

Table 1. Extinction coefficients at $\lambda \max$ for fulgimides in toluene

\begin{tabular}{|c|c|c|}
\hline \multirow{2}{*}{ Compound (Medium) } & \multicolumn{2}{|c|}{$\lambda_{\max } / \mathrm{nm}\left(\mathcal{E}_{\max } / \mathrm{mol}^{-1} \mathrm{~L} \mathrm{~cm}^{-1}\right)$} \\
\hline & $E$-form & $C$-form \\
\hline N-Alkyindolylfulgimide $\mathbf{1}$ (Toluene) & $365\left(6.1 \times 10^{3}\right)$ & $571\left(5.3 \times 10^{3}\right)$ \\
\hline N-Arylindolylfulgimide 2 (Toluene) ${ }^{65}$ & $367\left(6.6 \times 10^{3}\right)$ & $574\left(6.0 \times 10^{3}\right)$ \\
\hline 1-co- PAA (Acetate buffer) & 368 & 591 \\
\hline 1-co- PAA (Phosphate buffer) & 372 & 588 \\
\hline 2-co- PAA (Acetate buffer) ${ }^{65}$ & 377 & 596 \\
\hline 2-co- PAA (Phosphate buffer) ${ }^{65}$ & 379 & 590 \\
\hline
\end{tabular}




\subsubsection{Thermal and hydrolytic stability}

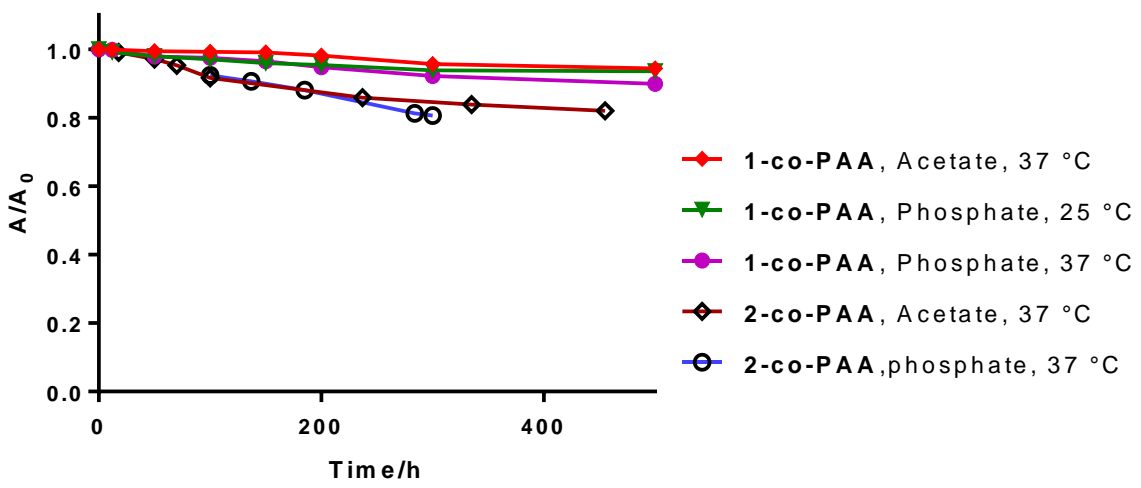

Figure 18. The $\mathrm{E}$ form decomposition in $50 \mathrm{mM}$ phosphate $(\mathrm{pH} \mathrm{7.4)}$ and 50 $\mathrm{mM}$ acetate buffer ( $\mathrm{pH}$ 5.0). Data for 2-co-PAA from ref.65.

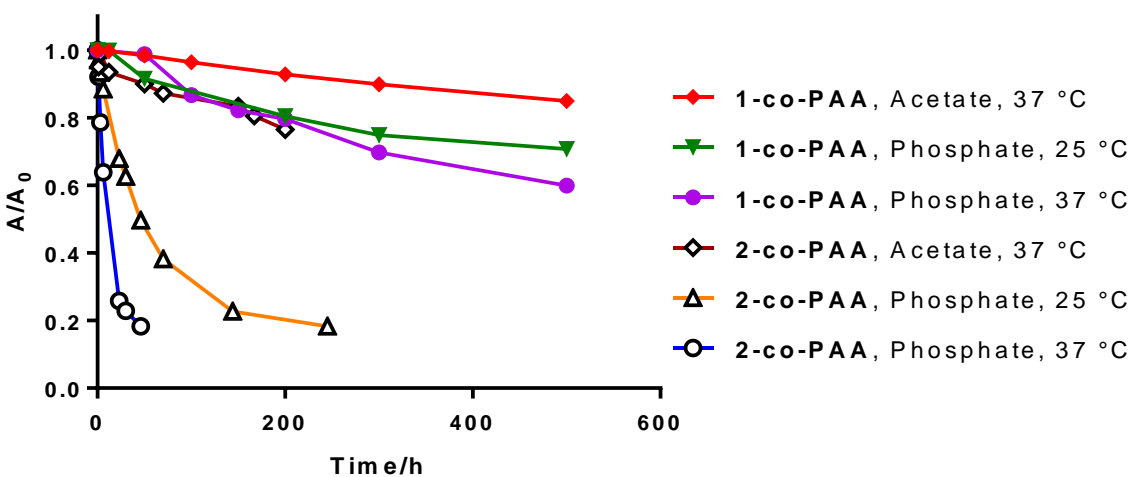

Figure 19. The $\mathrm{C}$ form decomposition in $50 \mathrm{mM}$ phosphate $(\mathrm{pH} \mathrm{7.4)}$ and 50 $\mathrm{mM}$ acetate buffer ( $\mathrm{pH}$ 5.0). Data for 2-co-PAA from ref. 65.

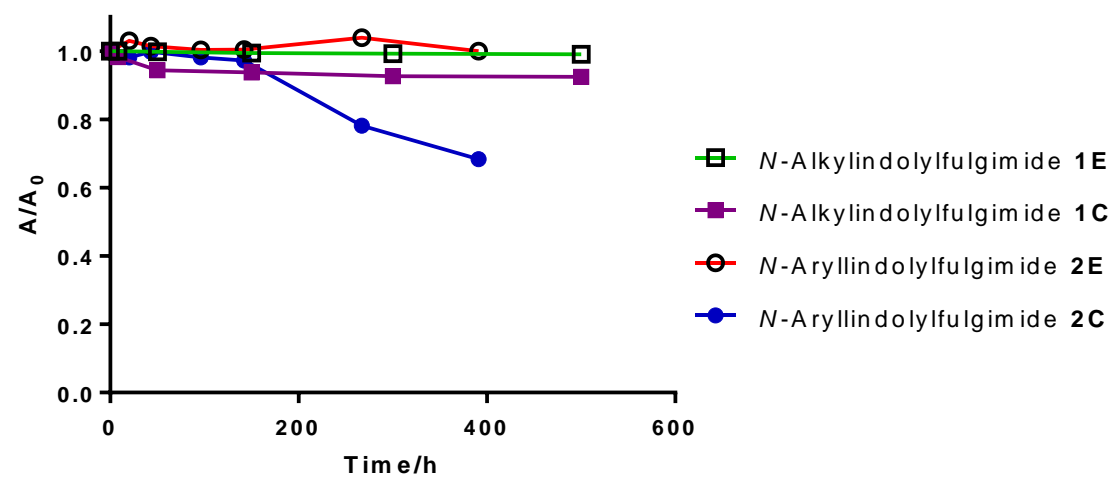

Figure 20. Decomposition of $\mathrm{N}$-alkylfulgimide 1 and $\mathrm{N}$-arylfulgimide 2 in toluene at $80 \stackrel{\circ}{ } \mathrm{C}$. Data for $\mathrm{N}$-arylfulgimide 2 from ref. 65 . 
The stability of the $C$ and $E$ forms of $N$-alkylindolylfulgimide 1 was studied in toluene at $80^{\circ} \mathrm{C}$. The $E$ and $C$ forms, were very stable, degradation rate was $<1 \mathrm{x}$ $10^{-3} \mathrm{~h}^{-1}$. Figure 20 . The $C$ form showed improved stability compared with a previously studied $\mathrm{N}$-arylindolylfulgimide. ${ }^{65}$ The hydrolytic stability of 1-co-PAA was studied in acetate and phosphate buffer at 25 and $37^{\circ} \mathrm{C}$. In both buffers the $E$ form of 1-co-PAA exhibited enhanced stability relative to the $C$ form. In acetate buffer at $37^{\circ} \mathrm{C}$, the hydrolytic stability of the $E$ form of 1-co-PAA is increased by the factor of 3 in comparison to $C$ form. In phosphate buffer, hydrolytic stability of $E$ form of 1-co-PAA is increased by the factor of 4 in comparison to the $C$ form. In addition, both forms of 1-co-PAA were slightly stable in acetate buffer than in phosphate buffer Table 2. The degradation rate of the 1-co-PAA $C$ form is 50 fold slower than that of the 2-co-PAA $C$ form in phosphate buffer at $\mathrm{pH} 7.4$ and $37^{\circ} \mathrm{C}$. . It was reported that $N$-ethylmaleimide ( $N$-alkylimide) is 25 times more stable than $\mathrm{N}$-phenylmaleimide ( $\mathrm{N}$-arylimide) in a phosphate buffer at $\mathrm{pH} 7.0 .61$ The rate of degradation of 1-co-PAA in phosphate is slightly higher than in acetate buffer, which shows that this $\mathrm{pH}$ range has only a limited effect on the rate of hydrolysis. It has been previously reported that rate of hydrolysis of $\mathrm{N}$-alkylmaleimide is base catalyzed in $\mathrm{pH}$ range between 7 and 9 , and is independent of the $\mathrm{pH}$ below $\mathrm{pH} 4$. However the introduction of phenyl on nitrogen provides an effective positive charge on the imide carbonyl, which results in an increase in the rate of hydrolysis. Between $\mathrm{pH} 5$ and $7.4 .^{62}$

Table 2. Decomposition of fulgimides at $80^{\circ} \mathrm{C}$ and copolymers at $37^{\circ} \mathrm{C}$ 


\begin{tabular}{lcc}
\hline \multicolumn{1}{c}{ Compound (Medium) } & \multicolumn{2}{c}{ Decomposition rate $\left(\times 10^{3}, \mathrm{~h}^{-1}\right)^{\mathrm{a}}$} \\
\cline { 2 - 3 } & Open forms & Close forms \\
\hline N-Alkylfulgimide 1 (Toluene) & 0.02 & 0.21 \\
N-Arylfulgimide 2 (Toluene) & & 0.82 \\
1-co-PAA (Acetate buffer) & $<0.01$ & 0.34 \\
1-co-PAA (Phosphate buffer) & 0.11 & 1.1 \\
2-co-PAA (Acetate buffer) & & 0.23 \\
2-co-PAA (Phosphate buffer) & 0.71 & 1.0 \\
\hline
\end{tabular}

a Data fit to a single exponential decay.

\subsubsection{Photochemical Stability}

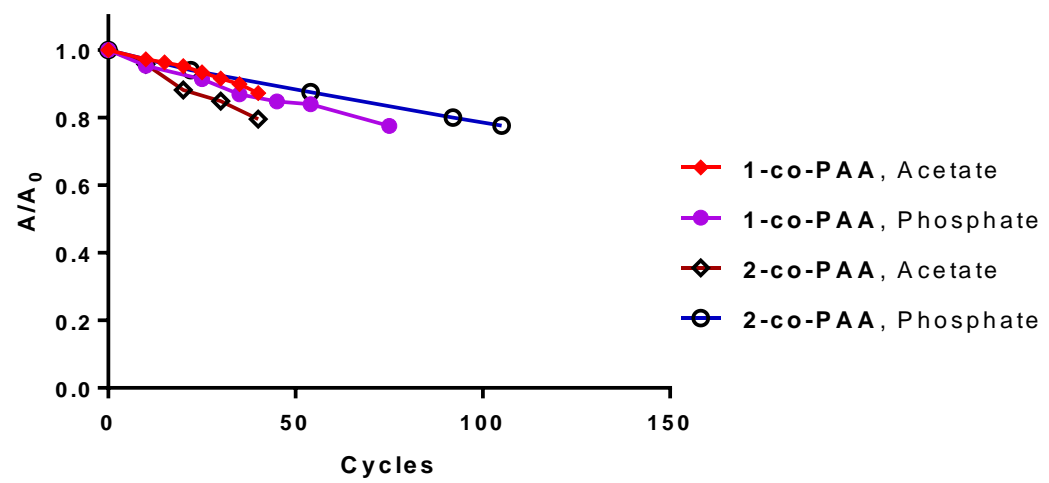

Figure 21. Photochemical decomposition of 1-co-PAA and 2-co-PAA in $50 \mathrm{mM}$ phosphate $(\mathrm{pH} 7.4)$ and $50 \mathrm{mM}$ acetate buffer $(\mathrm{pH} \mathrm{5.0)}$. Data for 2-co-PAA from ref. 65.

The photochemical stability of $\mathrm{N}$-Alkylindolylfulgimide and its corresponding copolymer were studied in toluene and buffers, respectively. In toluene, $\mathrm{N}$ alkylindolylfulgimide 1 underwent 507 photochemical cycles before degrading by $20 \%$, Figure 22 . The decomposition rate of the monomer 1 is $0.03 \%$ per cycle, 


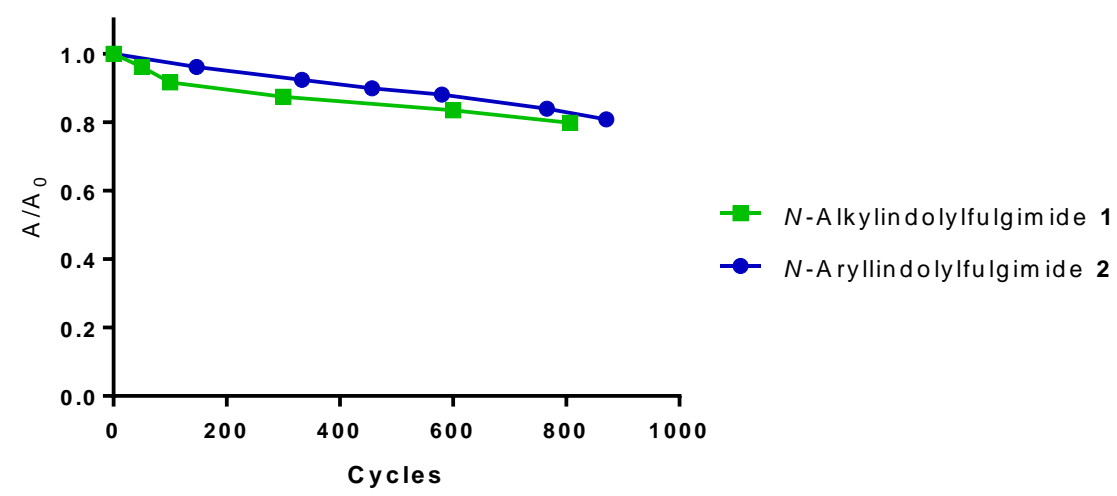

Figure 22. Photochemical decomposition of $\mathrm{N}$-alkylfulgimide 1 and $\mathrm{N}$ arylfulgimide 2 in toluene. Data for $\mathrm{N}$-arylfulgimide 2 from ref. 65 .

which is similar to that of $\mathrm{N}$-arylindolyfulgimide $2 .{ }^{65}$ The decomposition rates of the copolymer were faster in buffers than the monomer in toluene. The copolymer degradation rate is almost similar in acetate buffer as in phosphate buffer, Figure 21. In phosphate buffer 1-co-PAA underwent 76 cycles before degrading $23 \%$, Table 3. The degradation rates are higher in aqueous solutions. These results are consistent with previous studies which reported that the large dipole molecule of the $C$ form have strong interaction with the polar solvents. This strong interaction lower the transformation process by increasing the activation energy of the reaction. Consequently, fulgimides copolymers have lower quantum yields (longer cycling time) in polar solvents vs nonpolar solvents. ${ }^{12,55,63,65}$. The lower quantum yield increase the cycling time and thus the sample needs to be illuminate for a longer time for a given number of cycles. This results in increased degradation rate.

Table 3. Photochemical stability of fulgimides and copolymers at room temperature 


\begin{tabular}{|c|c|c|c|c|c|}
\hline \multirow[t]{2}{*}{ Compound (Medium) } & \multicolumn{2}{|c|}{ Cycling time (s) } & \multicolumn{3}{|c|}{$\begin{array}{l}\text { Photochemical } \\
\text { decomposition }\end{array}$} \\
\hline & $C-E$ & $E-C$ & Cycles & $\mathrm{A} / \mathrm{A}_{0}$ & $\%$ Per Cycle \\
\hline N-Alkylfulgimide 1 (Toluene) & 12 & 60 & 507 & 0.83 & 0.03 \\
\hline N-Arylfulgimide 2 (Toluene) ${ }^{65}$ & 20 & 100 & 871 & 0.81 & 0.02 \\
\hline 1-co-PAA (Acetate buffer) & 200 & 420 & 65 & 0.79 & 0.32 \\
\hline 1-co-PAA (Phosphate Buffer) & 155 & 190 & 76 & 0.77 & 0.30 \\
\hline 2-co-PAA (Acetate buffer) ${ }^{65}$ & 720 & 720 & 40 & 0.80 & 0.50 \\
\hline 2-co-PAA (Phosphate Buffer) ${ }^{65}$ & 120 & 300 & 105 & 0.78 & 0.20 \\
\hline
\end{tabular}

\section{CONCLUSION AND FUTURE DIRECTIONS}

\subsection{Conclusion}

A novel $\mathrm{N}$-alkylindolylfulgimide molecule having a vinylbenzyl group attached to the nitrogen atom of the imide ring, $\mathbf{1}$, was synthesized and copolymerized with acrylamide, 1-co-PAA. Copolymer 1-co-PAA exhibited significantly enhanced hydrolytic stability and similar photochemical properties as 2-co-PAA containing an $\mathrm{N}$-arylindolylfulgimide 2 . The previously reported copolymer of $\mathrm{N}$-arylind2014

/olylfulgimide was unstable in phosphate buffer. Therefore, the stability of fulgimides was improved by replacing the aryl group with an alkyl group. The degradation rate of the least stable $C$ form of 1-co-PAA was 50 times slower than that of 2-co-PAA in phosphate buffer at $\mathrm{pH}$ 7.4. However, in acetate buffer at $\mathrm{pH}$ 5.0 the decomposition rate was 3 times slower. The 1-co-PAA in $E$ form exhibited enhanced stability relative to the $C$ form in both buffers. The 1-co-PAA was more 
stable in acetate buffer than in phosphate buffer for both forms. The photochemical stability of 1-co-PAA both in acetate and phosphate buffer.

\subsection{Future research}

The future work involves two objectives. First, synthesis of crosslinked copolymer and second, applications of the aqueous soluble copolymer in aqueous environment need to be investigated.

The $\mathrm{N}$-alkylindolylfulgimide has enhanced hydrolytic stability in phosphate buffer. An $N$-alkylindolylfulgimide with doubly substituted vinylbenzyl group can be synthesized. The methyl group on the indolyl ring needs to be replace with vinylbenzyl chloride. A synthetic scheme is proposed, Scheme 13.

Additionally, fulgimides have the potential to be copolymerized with polymers. This crosslinked copolymer can be use a hydrogel. The photochromic fulgimide copolymers have many application. For example, it can used to turn "on" and "off" enzyme activity. The light induce activity is a save method for biological systems. The enzyme will be immobilized in polymer, and upon irradiation of the light photochromic compound will be transformed and enzyme will react with substrate, Figure 23. 


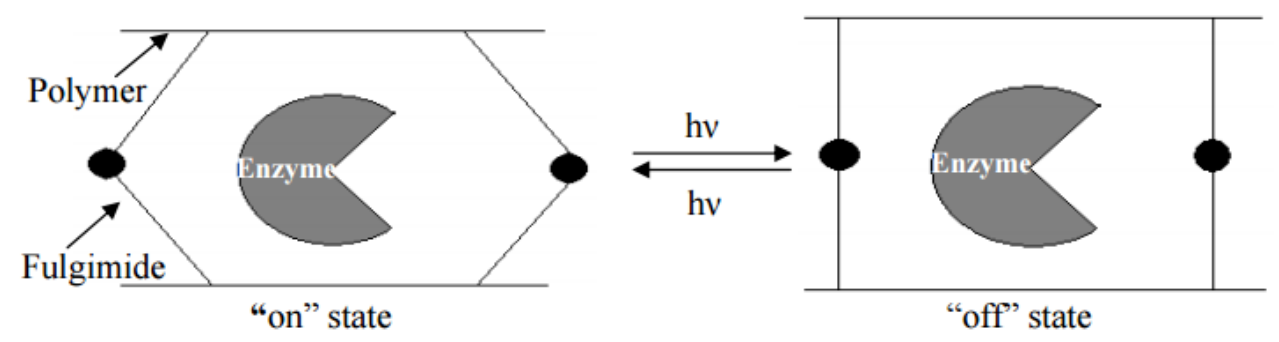

Figure 23. Enzyme immobilization by using photochromic copolymer

The trifluoromethyl dicycloproyl indolylfulgide is known for its excellent thermal stability. ${ }^{64}$ Derivation of this fulgide to the fulgimide by proposed scheme $15 \mathrm{might}$ result in highly stable trifluoromethyl dicycloproyl $\mathrm{N}$-alkylindolylfulgimide 4 in aprotic solvents, Scheme 15. 
Scheme 13. Proposed synthetic pathway of disubstituted $\mathrm{N}$ Alkylindolylfulgimide 3.

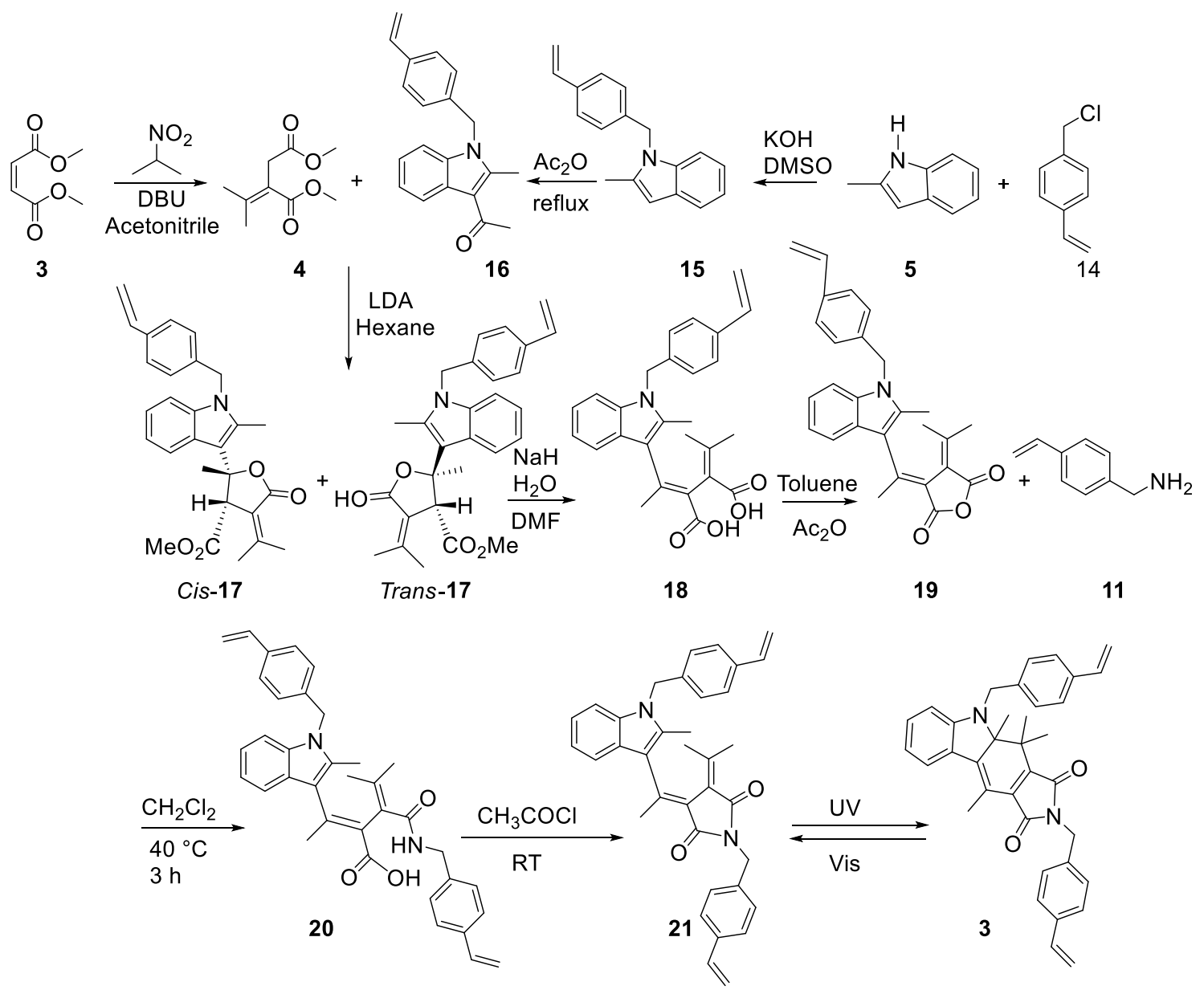


Scheme 14. Polymerization of disubstituted $\mathbf{N}$-Alkylindolylfulgimide.

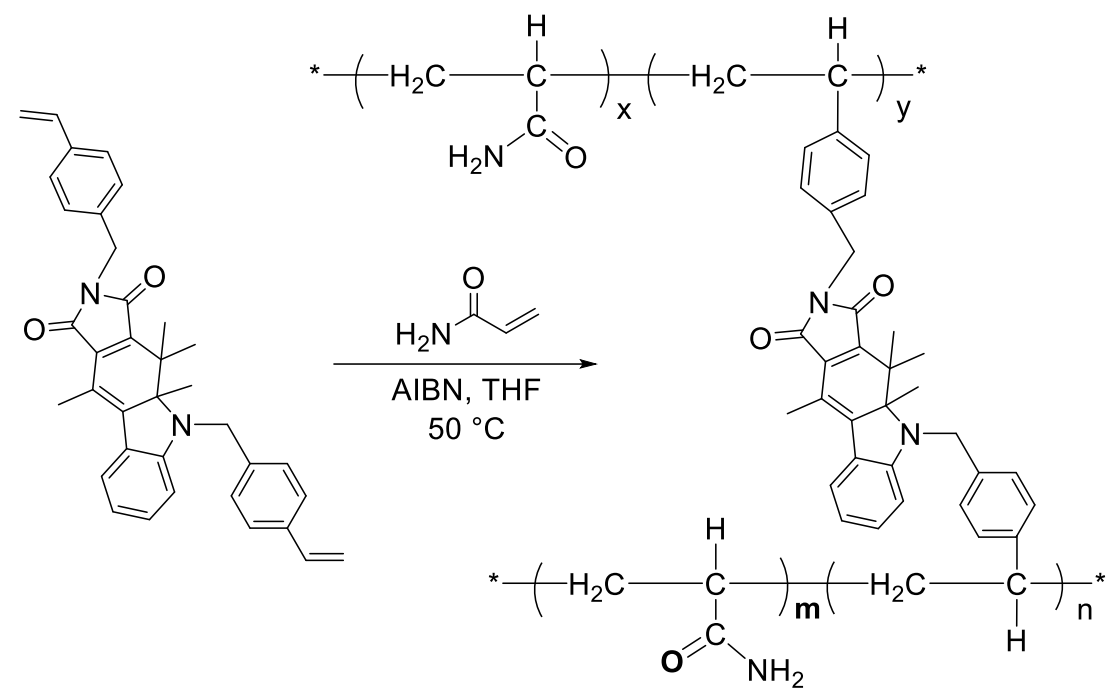

Scheme 15. Proposed synthetic pathway of trifluoromethyl dicycloproyl $\mathbf{N}$-Alkylindolylfulgimide 4.

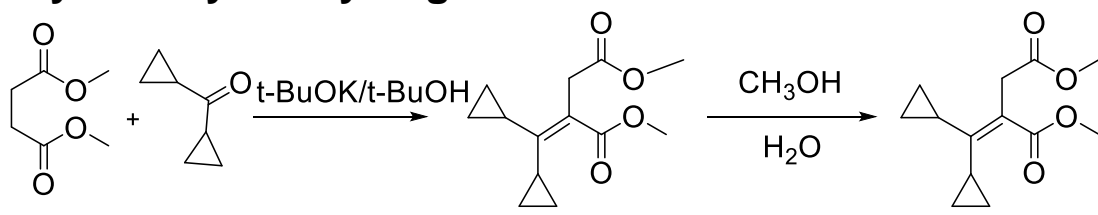
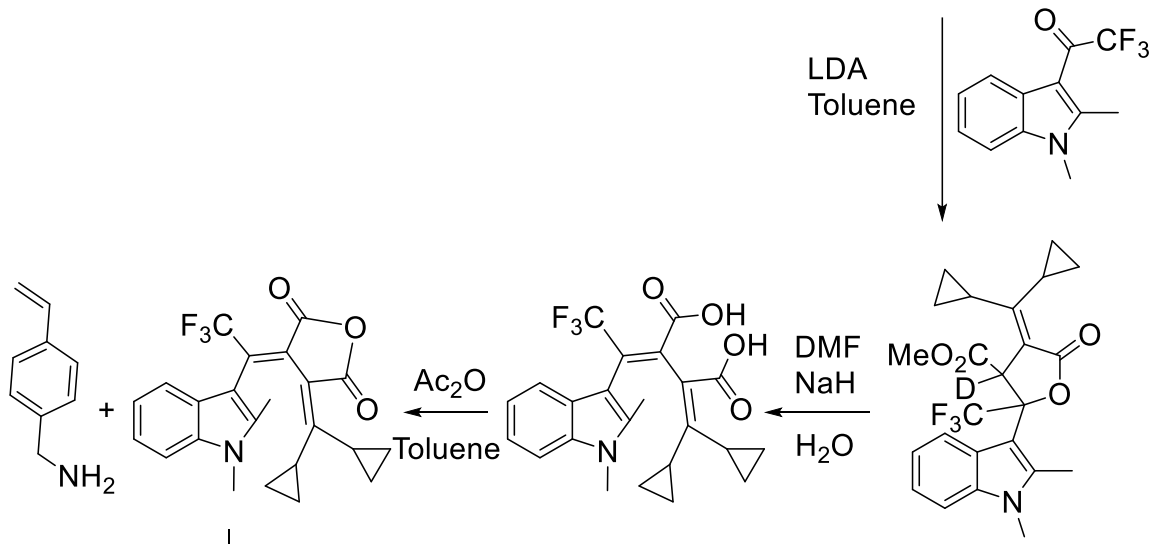

$40{ }^{\circ} \mathrm{C}$
$\mathrm{h}$ $\mathrm{CH}_{2} \mathrm{Cl}_{2}$

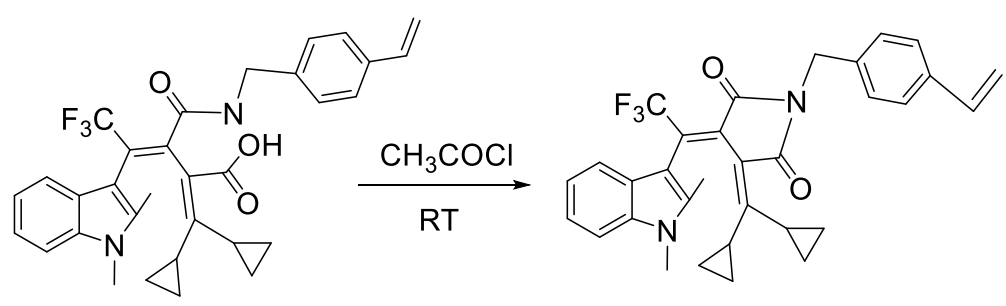




\section{REFERENCES}

(1) Crano, J. C.; Guglielmetti, R. J. Organic Photochromic and Thermochromic Compounds, Volume 1: Main Photochromic Families.; Plenum press: New York, 1999; pp 378.

(2) Irie, M. Photochromism of Diarylethene Molecules and Crystals. Proc. Jpn. Acad. Ser. B. Phys. Biol. Sci. 2010, 86, 472-483.

(3) Duerr, H.; Bouas-Laurent, H. Photochromism: Molecules and Systems: Revised Edition.; Elsevier Science: New York, 2003; pp 1044.

(4) Hirshberg, Y. Photochromy in the Bianthrone Series. Compt. rend. 1950, 231, 903-904.

(5) Berkovic, G.; Krongauz, V.; Weiss, V. Spiropyrans and Spirooxazines for Memories and Switches. Chem. Rev. (Washington, D. C.) 2000, 100, 17411753.

(6) Irie, M.; Mohri, M. Thermally Irreversible Photochromic Systems. Reversible Photocyclization of Diarylethene Derivatives. J. Org. Chem. 1988, 53, 803808.

(7) Irie, M. Photochromism: Memories and Switches-Introduction. Chem. Rev. (Washington, D. C.) 2000, 100, 1683.

(8) Irie, M. Diarylethenes for Memories and Switches. Chem. Rev. (Washington, D. C.) $2000,100,1685-1716$.

(9) Russew, M. M.; Hecht, S. Photoswitches: From Molecules to Materials. Adv. Mater. 2010, 22, 3348-3360.

(10) Dvornikov, A. S.; Liang, Y.; Tomov, I. V; Rentzepis, P. M. Write, Read, and Erase Materials for 3D Optical Memory Devices. Proc. SPIE-The Int. Soc. Opt. Eng. 1999, 3802, 192-200. 
(11) Huang, Y.; Li, F.; Ye, C.; Song, Y.; Qin, M.; Ran, W. A Photochromic Sensor Microchip for High-Performance Multiplex Metal Ions Detection. Sci. Rep. 2015, 5, 9724.

(12) Liang, Y.; Dvornikov, A. S.; Rentzepis, P. M. Solvent and Ring Substitution Effect on the Photochromic Behavior of Fluorescent 2-Indolylfulgide Derivatives. J. Photochem. Photobiol. A Chem. 1999, 125, 79-84.

(13) Wang, J.; Feng, C.; Hu, W. Progress of Photochromic Polymers. Huaxue Jinzhan. 2006, 18, 298-307.

(14) Liang, X.; Nishioka, H.; Takenaka, N.; Asanuma, H. A DNA Nanomachine Powered by Light Irradiation. Chem.BioChem. 2008, 9, 702-705.

(15) Toriumi, A.; Kawata, S.; Gu, M. Reflection Confocal Microscope Readout System for Three-Dimensional Photochromic Optical Data Storage. Opt. Lett. 1998, 23, 1924-1926.

(16) Islamova, N. I.; Chen, X.; DiGirolamo, J. A.; Silva, Y.; Lees, W. J. Thermal Stability and Photochromic Properties of a Fluorinated Indolylfulgimide in a Protic and Aprotic Solvent. J. Photochem. Photobiol. A Chem. 2008, 199, 85-91.

(17) Wolak, M. A.; Thomas, C. J.; Gillespie, N. B.; Birge, R. R.; Lees, W. J. Tuning the Optical Properties of Fluorinated Indolylfulgimides. J. Org. Chem. 2003, 68, 319-326.

(18) Heinz, B.; Malkmus, S.; Laimgruber, S.; Dietrich, S.; Schulz, C.; RueckBraun, K.; Braun, M.; Zinth, W.; Gilch, P. Comparing a Photoinduced Pericyclic Ring Opening and Closure: Differences in the Excited State Pathways. J. Am. Chem. Soc. 2007, 129, 8577-8584.

(19) Kumar, G. S.; Neckers, D. C. Photochemistry of Azobenzene-Containing Polymers. Chem. Rev. (Washington, DC, United States) 1989, 89, 19151925.

(20) Serna, P.; Corma, A. Transforming Nano Metal Nonselective Particulates into Chemoselective Catalysts for Hydrogenation of Substituted Nitrobenzenes. ACS Catal. 2015, 5, 7114-7121. 
(21) Gritsan, N. Photochromism of Quinones. Experimental and Quantum Chemical Study. Mol. Cryst. Liq. Cryst. Sci. Technol; Sect. A. 1997, 297, 167-174.

(22) Stobbe, H.; Leuner, K. Butadiene-Compounds. X. Two Cumyldimethylfulgenic Acids and a Third Isomeride. Berichte der Dtsch. Chem. Gesellschaft 1905, 38, 3897-3903.

(23) Stobbe, H. Butadiene Compounds. 7. Fulgenic Acid and Fulgide Dyes. Berichte der Dtsch. Chem. Gesellschaft.1905, 38, 3673-3682.

(24) Yokoyama, Y. Fulgides for Memories and Switches. Chem. Rev. (Washington, D. C.) 2000, 100, 1717-1739.

(25) Kaneko, A.; Tomoda, A.; Ishizuka, M.; Suzuki, H.; Matsushima, R. Photochemical Fatigue Resistances and Thermal Stabilities of Heterocyclic Fulgides in PMMA Film. Bull. Chem. Soc. Jpn. 1988, 61, 3569-3573.

(26) Matsushima, R.; Nishiyama, M.; Doi, M. Improvements in the Fatigue Resistances of Photochromic Compounds. J. Photochem. Photobiol. A Chem. 2001, 139, 63-69.

(27) Fan, M. G.; Yu, L.; Zhao, W. Fulgide Family Compounds: Synthesis, Photochromism, and Applications. In Org. Photochromic Thermochromic Compd.; Plenum Publishing Corp., 1999; pp. 141-206.

(28) Heller, H. G.; Elliot, C. C.; Koh, K.; Al-Shihry, S.; Whittall, J. The Design and Development of Photochromic Systems for Commercial Applications. Spectro Sc. 1993, 125, 156-168.

(29) Islamova, N. I.; Chen, X.; Fan, C. J.; Andino, R. S.; Lees, W. J. Photochromic Copolymers Containing 3-Indolylfulgides/indolylfulgimides: Synthesis and Photochemical Properties in Toluene and as Films. Polym. Degrad. Stab. 2013, 98, 1662-1670.

(30) Bowden, S. L.; Harris, S. A.; Heller, H. G.; Hewlins, M. J. E. Photochromic Heterocyclic Fulgides. Part 6. Base-Catalyzed Cyclizations of 1-(2,5Dimethyl-3-Furyl and 2,5-Dimethyl-3Thienyl)ethylidene(isopropylidene)succinic Anhydrides and Related Compounds. J. Chem. Soc. Perkin Trans. 1. 1992, 725-728. 
(31) Heller, H. G.; Langan, J. R. Photochromic Heterocyclic Fulgides. Part 3. The Use of (E)- $\alpha$-(2,5-Dimethyl-3-Furylethylidene)(isopropylidene)succinic Anhydride as a Simple Convenient Chemical Actinometer. J. Chem. Soc. Perkin Trans. 2 Phys. Org. Chem. 1981, 341-343.

(32) Yokoyama, Y.; Takahashi, K. Trifluoromethyl-Substituted Photochromic Indolylfulgide. A Remarkably Durable Fulgide towards Photochemical and Thermal Treatments. Chem. Lett. 1996, 1037-1038.

(33) Liang, Y.; Dvornikov, A. S.; Rentzepis, P. M. Photochemistry of Photochromic 2-Indolylfulgides with Substituents at the 1'-Position of the Indolylmethylene Moiety. J. Photochem. Photobiol. A Chem. 2001, 146, 8393.

(34) Thomas, C. J.; Wolak, M. A.; Birge, R. R.; Lees, W. J. Improved Synthesis of Indolyl Fulgides. J. Org. Chem. 2001, 66, 1914-1918.

(35) Matsushima, R.; Tomoda, A. Photochromism of Fulgides. Senryo to Yakuhin 1994, 39, 225-236.

(36) Wolak, M. A.; Thomas, C. J.; Gillespie, N. B.; Birge, R. R.; Lees, W. J. Tuning the Optical Properties of Fluorinated Indolylfulgimides. J. Org. Chem. 2003, $68,319-326$.

(37) Reddy, P. Y.; Kondo, S.; Toru, T.; Ueno, Y. Lewis AcidHexamethyldisilazane-Promoted Efficient Synthesis of N-Alkyl- and NArylimide Derivatives. J. Org. Chem. 1997, 62, 2652-2654.

(38) Liang, Y.; Dvornikov, A. S.; Rentzepis, P. M. Synthesis of Novel Photochromic Fluorescing 2-Indolylfulgimides. Tetrahedron Lett. 1999, 40, 8067-8069.

(39) Lee, W.-W. W.; Gan, L.-M.; Loh, T.P. Microwave-Assisted Synthesis of Photochromic Fulgimides. J. Photochem. Photobiol. A Chem. 2007, 185, 106-109.

(40) Deblauwe, V.; Smets, G. Quantum Yields of the Photochromic Reactions of Heterocyclic Fulgides and Fulgimides. 1988, 189, 2503-2512. 
(41) Liang, Y.; Dvornikov, a. S.; Rentzepis, P. M. Synthesis and Properties of Photochromic Fluorescing 2-Indolyl Fulgide and Fulgimide Copolymers. Macromol.Chem.Phys. 2002, 35, 9377-9382.

(42) Liang, Y.; Dvornikov, A. S.; Rentzepis, P. M. Photochromic Cross-Linked Copolymer Containing Thermally Stable Fluorescing 2-Indolylfulgimide. Chem. Commun. 2000,17, 1641-1642.

(43) Liang, Y.; Dvornikov, A. S.; Rentzepis, P. M. Synthesis and Properties of Photochromic Fluorescing 2-Indolyl Fulgide and Fulgimide Copolymers. Macromol.Chem.Phys. 2002, 35, 9377-9382.

(44) Matsushima, R.; Sakaguchi, H. Comparison of the Photochromic Properties of Fulgides and Fulgimides. J. Photochem. Photobiol. A Chem. 1997, 108, 239-245.

(45) Kose, M.; Orhan, E. Comparison of Photochromic Properties and Thermal Stabilities of Fulgide, Fulgimide, and benzimidazole[1,2-A]pyrrolidine-2-One Derivatives. Turkish J. Chem. 2009, 33, 579-588.

(46) Yokoyama, Y.; Tanaka, T.; Yamane, T.; Kurita, Y. Synthesis and Photochromic Behavior of 5-Substituted Indolylfulgides. Chem. Lett. 1991, 1125-1128.

(47) Union, I.; Pure, O. F.; Chemistry, A.; Division, O. C.; Photochemistry, C. O. N.; Bouas-laurent, H. ( IUPAC Technical Report ) Organic Photochromism ( IUPAC Technical Report ). 2001, 73, 639-665.

(48) Ilge, H. D.; Paetzold, R.; Radeglia, R. Photochemistry of Fulgides. XI. Carbon-13 Nuclear Magnetic Resonance Spectra of Phenylfulgides. J. fuer Prakt. Chemie. 1984, 326, 222-232.

(49) Crano, J. C.; Flood, T.; Knowles, D.; Kumar, A.; Van Gemert, B. Photochromic Compounds: Chemistry and Application in Ophthalmic Lenses. Pure Appl. Chem. 1996, 68, 1395-1398. 
(50) Yokoyama, Y.; Hayata, H.; Ito, H.; Kurita, Y. Photochromism of a Furylfulgide, $\quad$ 2-[1-(2,5-Dimethyl-3-Furyl)ethylidene]-3Isopropylidenesuccinic Anhydride, in Solvents and Polymer Films. Bull. Chem. Soc. Jpn. 1990, 63, 1607-1610.

(51) Irie, M.; Mohri, M. Thermally Irreversible Photochromic Systems. Reversible Photocyclization of Diarylethene Derivatives. J. Org. Chem. 1988, 53, 803808.

(52) Wolak, M. A.; Gillespie, N. B.; Thomas, C. J.; Birge, R. R.; Lees, W. J. Optical Properties of Photochromic Fluorinated Indolylfulgides. J. Photochem. Photobiol. A Chem. 2001, 144, 83-91.

(53) Wolak, M.; Sullivan, J.; Thomas, C. J.; Finn, R. C.; Birge, R. R.; Lees, W. J. Thermal Rearrangement of a Fluorinated Indolylfulgide: A Novel 1,5-Indolyl Shift. In Abstracts of Papers, 222nd ACS National Meeting, Chicago, IL, United States, August 26-30, 2001; J.Chem .Am. Soc . 2001;p.ORGN-307.

(54) Wolak, M. A.; Gillespie, N. B.; Birge, R. R.; Lees, W. J. Thermolysis of Fluorinated Cycloalkylidene Fulgides Yields a New Class of Photochromic Compounds. Chem. Commun. (Camb). 2003, 992-993.

(55) Chen, X.; Islamova, N. I.; Robles, R. V; Lees, W. J. Photochromic Properties of a Water-Soluble Methyl Carboxylic Acid Indolylfulgimide. Photochem. Photobiol. Sci. 2011, 10, 1023-1029.

(56) Chen, X.; Islamova, N. I.; Garcia, S. P.; Di Girolamo, J. A.; Lees, W. J. Synthesis of Novel Indolylfulgimides. In Abstracts of Papers, 239th ACS National Meeting, San Francisco, CA, United States, March 21-25, 2010; J. Am.Chem. Soc. 2010; p. ORGN - 799.

(57) Walz, J.; Ulrich, K.; Port, H.; Wolf, H. C.; Wonner, J.; Effenberger, F. Fulgides as Switches for Intramolecular Energy Transfer. Chem. Phys. Lett. 1993, 213, 321-324.

(58) Ramsteiner, I. B.; Hartschuh, A.; Port, H. Relaxation Pathways and Fs Dynamics in a Photoswitchable Intramolecular D $\rightarrow$ A Energy Transfer System. Chem. Phys. Lett. 2001, 343, 83-90. 
(59) Liang, Y. C.; Dvornikov, A. S.; Rentzepis, P. M. Nonvolatile Read-out Molecular Memory. Proc. Natl. Acad. Sci. U. S. A. 2003, 100, 8109-8112.

(60) Gust, D.; Andreasson, J.; Pischel, U.; Moore, T. A.; Moore, A. L. Data and Signal Processing Using Photochromic Molecules. Chem. Commun. 2012, 48, 1947-1957.

(61) Machida, M.; Machida, M. I.; Kanaoka, Y. Fluorescent Thiol Reagents. Part XIV. Hydrolysis of N-Substituted Maleimides: Stability of Fluorescence Thiol Reagents in Aqueous Media. Chem. Pharm. Bull. (Tokyo). 1977, 25, 27392743.

(62) Matsui, S.; Aida, H. Hydrolysis of Some N-Alkylmaleimides. J. Chem. Soc. Perkin Trans. 2 Phys. Org. Chem. 1978, 1277-1280.

(63) Chen, X.; Islamova, N. I.; Garcia, S. P.; DiGirolamo, J. A.; Lees, W. J. Synthesis and Optical Properties of Aqueous Soluble Indolylfulgimides. J. Org. Chem. 2009, 74, 6777-6783.

(64) Islamova, N. I.; Chen, X.; Garcia, S. P.; Guez, G.; Silva, Y.; Lees, W. J. Improving the Stability of Photochromic Fluorinated Indolylfulgides. J. Photochem. Photobiol. A Chem. 2008, 195, 228-234.

(65) Changjun Fan. Synthesis and characterization of photochromic copolymerscontaining 3-indolylfulgides/ndolylfulgimides. Ph.D dissertation, Florida International University, Miami, FL, Oct 2015.

(66) Pavia, L. Lampman, M. Kriz, S. Introduction to spectroscopy, $3^{\text {rd }}$ ed.; Harcourt: New York, 2001; pp 353-389. 